\title{
A Novel Group Therapeutic Format in Cognitive Behavioral Treatment for Clients with Social Phobia in a Training Setting: A Case Study of One Treatment Group with Nine Clients
}

\author{
ESBEN HOUGAARD ${ }^{\text {a,b }}{ }^{\text {, SARAH S. MADSEN }}{ }^{\mathrm{a}}$, LINE M. HANSEN ${ }^{\mathrm{a}}$, \\ METTE JENSEN ${ }^{\text {a }}$, GRO S. KATBORG ${ }^{\text {a }}$, LARS MORSAA ${ }^{\mathrm{a}}$, \\ MARIE PEDERSEN ${ }^{\text {a }}$, SIGNE M. PEDERSEN ${ }^{\text {a }}$, \& JACOB PIET ${ }^{\text {a }}$ \\ ${ }^{\mathrm{b}}$ Correspondence concerning this article should be addressed to Esben Hougaard, Psychological Department, \\ University of Aarhus, Nobelparken, Jens Chr. Skous Vej 4, 8000 Aarhus C, Denmark.
}

${ }^{a}$ Psychological Department, University of Aarhus, Denmark

Email: esbenh@psy.au.dk

\begin{abstract}
This case study pilot-tests a novel, cognitive behavioral treatment (CBT) program for social phobic clients in an Anxiety Clinic run by the Department of Psychology of the University of Aarhus, Denmark. The core of the program was an intensive therapy group lasting for 5 consecutive days during one week, from 9:00 am to 2:00 pm each day. The group was composed of 9 clients and 8 student therapists in training, who were present throughout the total 25 hours, and two supervising psychologists, who were present during the first 2 hours of each day. Each client was also assigned to one of the student therapists, seeing the therapist for 2-4 individual sessions before the intensive group-week, and 6 weekly 2-hour group sessions after the intensive group experience. The groups were composed of 4 (or 5) clients and 4 students with the students on their own in charge of the therapy. Individual therapy was also provided when clinically indicated after the end of the group therapy. Treatment was evaluated within an embedded case study design with one group and 9 clients via both qualitative information and quantitative measures that assessed the clients' presenting problems and therapeutic progress over the entire course of therapy and at follow-up. The results show that the intensive group treatment was therapeutically valuable for the clients. Specifically, almost all the clients appreciated the intensive group treatment format, and most achieved fast symptomatic declines over the week. Outcomes of the full treatment program for the whole group were in line with results from studies on psychotherapy for social phobia provided by experienced therapists. The educational value of the program is commented on in the discussion.
\end{abstract}

Key words: social phobia; cognitive behavioral therapy (CBT); group therapy; case study; training in psychotherapy 
A Novel Group Therapeutic Format in Cognitive Behavioral Treatment for Clients with Social

Phobia in a Training Setting: A Case Study of One Treatment Group with Nine Clients

E. Hougaard, S.S. Madsen, L.M. Hansen, M. Jensen, G.S. Katborg,

L. Morsaa, M. Pedersen, S.M. Pedersen, \& J. Piet

Pragmatic Case Studies in Psychotherapy, http://pcsp.libraries.rutgers.edu

Volume 4, Module 4, Article 1, pp. 1-52, 12-15-08 [copyright by authors]

\section{CASE CONTEXT AND METHOD}

\section{Clinical Setting}

The study was carried out at the Anxiety Specialty Clinic at the Educational and Research Clinic of the Department of Psychology, University of Aarhus, Denmark, as part of a clinical training program. The Anxiety Clinic offers cognitive-behavioral treatment (CBT) free of charge for clients with anxiety disorders, mostly panic disorder and social phobia, provided by supervised student therapists. The 16 students in the program are in their eighth semester or later and the clients they see in the Anxiety Clinic are, ordinarily, their first clients in psychotherapy. Clients are recruited from an advertisement and the Clinic's website. They are invited to send in a brief description of their problems, which is used for diagnostic screening.

The training program has a span of two semesters and includes a theoretical course on CBT of anxiety and depression. The theoretical course consists of 12 three-hour classes plus 2 two-day workshops in the first semester, and 4 six-hour "conferences" with student presentations of their theoretical papers and case-reports in the second semester.

A special format of training and therapy is used, including an intensive group treatment program for one week with 8 (or in this case 9) clients, 8 students, and two psychologists. At first we try to find 8 clients with panic disorder and 8 clients with social phobia as their primary diagnoses so that each student initially can have one client in therapy with one of these disorders. The client is invited to a structured clinical interview based on the Anxiety Disorder Interview Schedule for DSM-IV (ADIS-IV; Brown, DiNardo \& Barlow, 1994) carried out by a clinical psychologist, with the presence of a student who is going to be the client's individual therapist. Where clients have the disorder in question as their primary diagnosis and are willing to accept the group treatment program, they are included in either the panic disorder or the social phobia group. Otherwise, they are offered individual treatment or, in rare cases, referred to another treatment facility.

In the case of the social phobia group, which is the focus of the present paper, we thus aimed at getting a group of 8 clients with social phobia, each with a student therapist for individual therapy. This objective is, however, not always achieved, so some students may have more than one client in the group program, and some may have none (e.g., because the initial diagnosis based on the client's self-description turned out to be incorrect). After the assessment interview the clients in the group program are offered 2-4 individual sessions with their student therapist. They then meet for an intensive group program each day from 9 am to 2 pm over 5 days in one week. The clinical psychologists lead the first two hours of the day with the whole group present and then design exercises, mostly to be carried out in small groups with 4 (or 5) clients and 4 students, with the students as therapists the rest of the day. The purpose of this format is to present students with therapeutic models and to provide them with the opportunity of gradually learning to be in charge of the group therapy. The content of the program is outlined in Table 1, and further described below in the section on treatment (note that all the tables and figures are at the end of the article). 
A Novel Group Therapeutic Format in Cognitive Behavioral Treatment for Clients with Social

Phobia in a Training Setting: A Case Study of One Treatment Group with Nine Clients

E. Hougaard, S.S. Madsen, L.M. Hansen, M. Jensen, G.S. Katborg,

L. Morsaa, M. Pedersen, S.M. Pedersen, \& J. Piet

Pragmatic Case Studies in Psychotherapy, http://pcsp.libraries.rutgers.edu

Volume 4, Module 4, Article 1, pp. 1-52, 12-15-08 [copyright by authors]

After the intensive group therapy the clients are offered 6 weekly group sessions each lasting two hours in groups of 4 (or 5) clients and 4 students, with the students in turn leading the meetings. Clients are placed in groups together with their individual therapists, and students are on their own in charge of the therapy. A follow-up group meeting takes place about two months after the end of group treatment. Based on clinical need some clients are offered supplementary individual therapy with their student therapist, mostly 5-15 sessions. As a general rule, this further individual therapy is offered after the 6 weekly group sessions, although in a few cases individual therapy starts already in the period of the group therapy due to clients' urgent needs or because their attendance at the group meetings is impossible.

After this initial training in the group program students have at least one, and more often several clients with anxiety disorders in individual therapy. Weekly supervision in groups of 8 students is provided throughout the whole therapy period except in the intensive group-week, where there is half an hour of reflections each day after the treatment. Thus, all supervision is in groups, except for a few individual contacts with students in need of immediate support or advice. Over all, there are about 32 two-hour sessions of group supervision, in this case run by the first author (EH). The students are obliged to write a systematic case-report about one of their clients according to the template of this Pragmatic Case Studies in Psychotherapy journal as part of their examination for the course.

\section{The Rationale for Selecting The Clients}

Clients for the social phobia group program were recruited in the clinic's second year, and thus the second time the intensive treatment program was used (in the first year there were some problems with details of the program). The first eight clients in the semester applying for treatment at the clinic with social phobia as their primary diagnosis were offered treatment in the social phobia group. All clients agreed (the intensive group program was described at the website and thus known by most clients before applying for treatment). One client with an ethnic background (Laila) had social phobia problems but not enough for a formal diagnosis. She was, however, offered treatment in the group program because of initial lack of clients with diagnosable social phobia. Shortly thereafter, several suitable clients with urgent needs applied for treatment so we enhanced the group to nine clients. The clients were thus selected consecutively and not for being especially matched to a particular clinical or theoretical point apart from their diagnosis.

\section{Aim of the Study}

The primary aim of the study is to pilot-test the new treatment format for social phobia clients. The program was arranged with a focus on its educational value, and it might be less obvious that its specific format, e.g. to treat social phobic clients in groups with 18-19 persons 5 days in a week, also is valuable for the treated clients. Actually, some of the supervisors in the program had considerable doubts prior to the program's first realization. It is, thus, important to investigate how the clients respond to the treatment. 
A Novel Group Therapeutic Format in Cognitive Behavioral Treatment for Clients with Social

Phobia in a Training Setting: A Case Study of One Treatment Group with Nine Clients

E. Hougaard, S.S. Madsen, L.M. Hansen, M. Jensen, G.S. Katborg,

L. Morsaa, M. Pedersen, S.M. Pedersen, \& J. Piet

Pragmatic Case Studies in Psychotherapy, http://pcsp.libraries.rutgers.edu

Volume 4, Module 4, Article 1, pp. 1-52, 12-15-08 [copyright by authors]

\section{Methods}

\section{Case Studies and Case-Based Reasoning}

The scientific legitimacy of case studies has been argued with reference to case-based reasoning (Fishman, 2005; Kolodner, 1997), which is contrasted with rule-based reasoning. Rules are general knowledge about a problem domain presented in the formula of: "if $<$ condition $>$ then $<$ conclusion $>$ ", with variables within conditions and conclusions being logical connected by AND, OR, NOT etc. (Prentzas \& Hatzilugeroudis, 2007). Rules can be added into algorithms, and treatment algorithms are highly valued within evidence-based treatment. Rulebased analysis profits from being based on simple, economic knowledge representations, precision with regard to action prescriptions, allowing for replacement of distinct rules with new knowledge, and from providing explicit reasons for practical decisions. Its disadvantages include that there might be few precise rules for many practical problems, especially for rare or complex cases, that it could miss idiographic and contextual information, and that it does not allow for gradual change due to day-to-day learning.

Case-based analysis, on the other hand, consists in matching a new case, a person or situation, with a repertoire of earlier experienced or described cases, i.e., it draws on specific knowledge in particular contexts (Prentzas \& Hatzilugeroudis, 2007). Case-based reasoning profits from taking individuality and context into account, it can be used with new or complex cases, and the knowledge base is flexible upgraded through experiences with new cases. Casebased reasoning is in accordance with the way many professionals think in their daily practice (cf. Schön, 1986), as well as with theories of practice knowledge based on pragmatism or hermeneutic philosophy (Dias, 2007; Fishman, 2005). Its disadvantages include that cases do not represent general knowledge, a possible lack of relevant case-examples, problems with matching cases for similarity, and difficulties with clearly explaining why a certain line of action was taken.

Within the study of knowledge systems it is generally assumed that a combination of rule-based and case-based reasoning has advantages above using only one of the two ways of reasoning (Prentzas \& Hatzilygeroudis, 2007). This assumption was supported in a recent study of early treatment planning in a youth psychiatric institution in Hong Kong (Wang et al., 2007). The possibility of case-based reasoning makes every case a potential source of knowledge, which might be considered an important methodological background for the study of individual cases.

\section{$\underline{\text { Design }}$}

According to Yin (1991), a case study design includes 1) the study's question, 2) its propositions, 3) its unit of analysis, 4) the logic of linking data to propositions, and 5) the criteria for interpreting the findings. The two last points are further developed later in the section on methods. The study deals, in a general sense, with a practical evaluation of this particular treatment program (1). Within this broader scope of the study question the propositions (2) primarily focus on the program's effectiveness and feasibility for the clients. Secondarily the study explores causes of differences in treatment response of individual clients and the 
A Novel Group Therapeutic Format in Cognitive Behavioral Treatment for Clients with Social

Phobia in a Training Setting: A Case Study of One Treatment Group with Nine Clients

E. Hougaard, S.S. Madsen, L.M. Hansen, M. Jensen, G.S. Katborg,

L. Morsaa, M. Pedersen, S.M. Pedersen, \& J. Piet

Pragmatic Case Studies in Psychotherapy, http://pcsp.libraries.rutgers.edu

Volume 4, Module 4, Article 1, pp. 1-52, 12-15-08 [copyright by authors]

correspondence between outcome on quantitative client self-report scales and on clinical judgments based on qualitative information ("triangulation"). Although the primary purpose of the program is psychotherapeutic training of students, the educational aspects of the program were not formally studied except for a short course evaluation questionnaire. Some comments on the program's educational value is, however, offered in the final section 8 of the paper. The study is an embedded case study (Yin, 1991) with both group and individual clients as units of analysis (3). On a group level, the evaluation of the program is based on mean effect sizes on outcome measures and number of clients responding (4). On the individual level, cases are studied by means of qualitative and quantitative information (4). Since space does not permit a full presentation of all 9 cases according to the guidelines for pragmatic case studies (Fishman, 2000; 2005), the individual "case vignettes" should, primarily, be considered illustrations of the treatment procedures, the clients, their course of treatment and responses to this specific therapy program. Most of the vignettes are summaries of the students' more elaborated case reports.

\section{Procedures}

All clients were diagnosed with the ADIS-IV (DiNardo et al., 1994), a reliable, structured interview for anxiety disorders and related conditions according to DSM-IV. The diagnoses were made by the first author $(\mathrm{EH})$, who has more than 10 years of experience in using ADIS-IV in a psychiatric outpatient setting. The SCID-II Personality Questionnaire (SCID-II-Q) (First et al., 1997) was given to assess disordered personality traits; however, no structured interview for personality disorders was made.

Each individual and group session was videotaped for supervision. Also for each individual session, the therapist wrote up case notes and personal reflections, about 1-2 pages per session about their client(s). The videotapes were, however, not systematically studied (the clients were informed that the recordings would be erased within a month). In group therapy one of the students took notes of the therapeutic work in the session. This report with first names only was then mailed to the clients or given to them the next day, as therapeutic feedback.

\section{$\underline{\text { Measures }}$}

The following, standardized self-report scales were used for measuring symptoms and outcome (the results on these scales are listed in Tables 3, 4 and 5).

1. Beck Anxiety Inventory (BAI; Beck \& Steer, 1993). The BAI has 21 items, which are scored for presence in the last week from "0-never" to "3-almost all the time." It is, primarily, a measure of anxiety symptoms related to autonomic activation.

2. Beck Depression Inventory, second edition (BDI-II; Beck, Steer \& Brown, 1996). Similar in format to the BAI, the BDI is, by far, the most widespread depression questionnaire in clinical research and practice.

3. Social Phobia Scale (SPS; Mattick \& Clarke, 1998). The SPS has 20 items which are scored from "0not at all characteristic" to "4-very much characteristic for you." It is, primarily, a measure of fear of 
A Novel Group Therapeutic Format in Cognitive Behavioral Treatment for Clients with Social

Phobia in a Training Setting: A Case Study of One Treatment Group with Nine Clients

E. Hougaard, S.S. Madsen, L.M. Hansen, M. Jensen, G.S. Katborg,

L. Morsaa, M. Pedersen, S.M. Pedersen, \& J. Piet

Pragmatic Case Studies in Psychotherapy, http://pcsp.libraries.rutgers.edu

Volume 4, Module 4, Article 1, pp. 1-52, 12-15-08 [copyright by authors]

specific achievement situations, and thus especially relevant for specific social phobia. Like the SIAS, mentioned below, it is widely used in research on social phobia.

4. Social Interaction Anxiety Scale (SIAS; Mattick \& Clarke, 1998). The SIAS has 19 items and is scored in the same way as SPS. It is, primarily, a measure of interaction anxiety, and thus especially relevant for generalized social phobia.

5. Symptom Checklist, 90-item version (SCL-90; Derogatis, 1977). The SCL-90 has, as its name implies, 90 items, which are scored from "0-not at all" to "4-very much." It is, probably, the most widely used measure of general psychiatric complaints in psychotherapy research, with the scale's General Symptom Index (GSI), the mean score on all filled items, as the main measure of outcome.

6. Inventory of Interpersonal Problems - Circumplex version (IIP-C; Horowitz et al., 2000). The IIP-C has 64 items concerning interpersonal actions which are either difficult for the person or which he or she does too much, with each item scored from "0-not at all" to "4-very much". The IIP-C is widely used as a measure of personality in psychotherapy research.

All scales have acceptable psychometric properties (see Appendix B), and they are all recommended as measures of outcome in psychotherapy research (Strupp, Horowitz \& Lambert, 1997). It is generally recommended to use scales of disorder-specific symptoms as the primary measures of outcome in psychotherapy research (Strupp et al., 1997). Thus, we consider the two measures of social phobic symptoms, SPS and SIAS, the primary self-report measures of outcome in this study.

Besides these standardized measures, clients made ratings on five individualized scales, the "Evaluation of Social Phobia" (Appendix A) with ratings from "0-Not at all" to " 10 -Very much" of the extent of their anxiety, depression, and their specific social phobia patterns, including how much they "avoided your most feared social situations," "used your most preferred forms of safety behaviors" in these types of situations, and "believed in your most common negative, anxiety provoking thoughts about what might happen in the feared social situations." The individualized, qualitative content of the scales was filled collaboratively by the client and therapist after two or three individual sessions. The scales were planned to function as idiographic measures of outcome throughout therapy. However, they were inconsistently collected except for the intensive week, and thus, the results are only reported for this part of treatment.

At the time of the latest contact with the client, the client's individual therapist together with his supervisor scored the client's overall progress on the Clinical Global Impression Scale (CGI; Guy, 1976). The CGI has seven points from 1 ("very much improved") to 7 ("very much worse"), with the score 4 corresponding to "no change." It is a global measure without detailed descriptions of anchor points, but it is in accordance with the way clinicians often think about outcomes of clients. The scale has been used as the primary outcome measure in several large randomized clinical trials (e.g., Davidson et al., 2005; Heimberg et al., 1998). The scoring was done without regard to the scores on the quantitative measures, which were unknown to the supervisor at the time, and it was based on the latest, available qualitative information on the clients. 
A Novel Group Therapeutic Format in Cognitive Behavioral Treatment for Clients with Social

Phobia in a Training Setting: A Case Study of One Treatment Group with Nine Clients

E. Hougaard, S.S. Madsen, L.M. Hansen, M. Jensen, G.S. Katborg,

L. Morsaa, M. Pedersen, S.M. Pedersen, \& J. Piet

Pragmatic Case Studies in Psychotherapy, http://pcsp.libraries.rutgers.edu

Volume 4, Module 4, Article 1, pp. 1-52, 12-15-08 [copyright by authors]

\section{Figure 1. Flowchart of Treatment and Data Points}

As shown in Figure 1, all the quantitative scales were given before therapy and at followup, either two months after the end of group treatment or at the end of individual therapy, if this came later. Scales 1 to 4 -- the BAI, the BDI-II, the SPS, and the SIAS -- were administered at the end of the weekly group treatment.

\section{Definitions of Outcome}

Outcome on the six, standardized, client self-report scales listed above was categorized according to the following rules (see Appendix B, "Measuring Change," for psychometric values and calculations):

1. Statistically significant change was calculated according to Jacobson and Truax's (1991) method based on the psychometric properties of scales. We used coefficients of internal consistency (Cronbach's alpha) and values from non-clinical samples in the calculations (cf. Bauer, Lambert, \& Nielsen, 2004).

2. According to Jacobson and Truax's (1991) criteria, clinical change is defined as "end-point status" below the cut-off point between a clinical and a non-clinical population on the scale, i.e., within the range of normal functioning rather than of psychopathological functioning. For the IIP-C measure, we used the cut-off point of one standard deviation (SD) above the mean of the normal standardization sample, since we were not aware of usable published norms from clinical populations for this scale.

3. Large change on a scale is defined as positive change on the scale that is more than one $S D$ of the scale. The relevant $S D$ was based on information in the scale's manual (or in other published information about the scale) for the most relevant comparison group, i.e., social phobic clients for the BAI, SPS and SIAS; and mixed psychiatric outpatients for the BDI-II and SCL-90. For IIP-C we used the SD of the normal standardization sample.

A global rating of outcome from the therapist's and supervisor's point of view was based on the CGI, with treatment response defined by the two highest values of the scale, i.e., "1-very much improved", and "2-much improved."

\section{Confidentiality}

Names and some biographical information have been changed to prevent disclosure of clients' identities, while at the same time striving to preserve the "clinical meaning" of the case.

\section{THE NINE CLIENTS IN THE GROUP}

Some demographic and clinically relevant data on the 9 individual clients are given in Table 2, including outcome on the Clinical Global Impression Scale (CGI); age; occupation; civil (marital) status; primary diagnosis; comorbid diagnoses if present; number of positive items on 
A Novel Group Therapeutic Format in Cognitive Behavioral Treatment for Clients with Social

the SCID-II-Q measure of characteristics associated with personality disorders; duration of the main presenting problem; drug and psychotherapy treatment history; and the number of sessions received across the whole program. Table 3 lists (a) the pre-treatment scores of the 9 individual clients, and (b) the means and standard deviations of scores on the six standardized measures for normative groups. Table 4 shows the respective means and standard deviations on the scales for the whole group.

As can be seen in Table 2, 8 of the 9 clients received a primary DSM-IV diagnosis of social phobia, with 5 of these having some comorbid involvement. The $9^{\text {th }}$ individual (Laila) had a primary, sub-threshold diagnosis of PTSD and a comorbid, sub-threshold diagnosis of social phobia. As can also be seen, the clients as a group were socially and occupationally rather well functioning, with 7 out of 9 being in work or education roles, and 7 out of 9 being married or living together with a boyfriend or girlfriend.

As can be seen in Table 4, the mean scores prior to treatment for the clients on the two measures of social phobic symptoms, SPS and SIAS, were $38.0(S D=15.2)$ and $41.2(S D=$ 17.4), respectively, compared to $40.0(S D=16.0)$ and $34.6(S D=16.4)$ in Mattick and Clarke's (1998) social phobia standardization sample (see Table 3J). In a large comparative study of group CBT and medication in the treatment of social phobia, also using SPS and SIAS, the pretreatment scores were $27.3(S D=17.1)$ and $41.8(S D=18.4)$, respectively (Heimberg et al., 1998). Thus, our sample appears to be rather similar to other social phobic clients in the clinic and/or in psychotherapy research with regard to severity of self-reported social phobic symptoms. All clients, except Laila (who did not have a formal diagnosis), were in the clinical, rather than the normal range on at least one of the two social phobia scales before treatment (see Tables 3A-3I).

Looking at the clinical histories of the 9 clients in Table 2, it can be seen that most had rather longstanding problems. Six out of the 8 clients with a formal diagnosis of social phobia scored above 20 on self-reported symptoms of personality disorder on the SCID-II-Q, a threshold McCullough, Kuhn, Andrews, Kaplan, Wolf \& Hurley (2003) clinically suggest for a patient's need for personality-focused psychotherapy. There are, however, no empirically based thresholds for the scale, and it is well-known that diagnosis of personality disorder based on self-report measures highly overestimates the number of cases. Since we did not use a structured interview for personality disorders, we only suggested "probable personality disorders" in two cases (see Table 2).

\section{GUIDING CONCEPTION WITH RESEARCH AND CLINICAL EXPERIENCE SUPPORT}

\section{A. Social Phobia}

The present treatment program is designed for clients with social phobia. Social phobia or social anxiety disorder is, according to DSM-IV (APA, 1994), a marked and persistent fear of social or performance situations in which embarrassment may occur, which leads to marked distress for the person or significantly interferes with his or her work, education or social 
A Novel Group Therapeutic Format in Cognitive Behavioral Treatment for Clients with Social

Phobia in a Training Setting: A Case Study of One Treatment Group with Nine Clients

E. Hougaard, S.S. Madsen, L.M. Hansen, M. Jensen, G.S. Katborg,

L. Morsaa, M. Pedersen, S.M. Pedersen, \& J. Piet

Pragmatic Case Studies in Psychotherapy, http://pcsp.libraries.rutgers.edu

Volume 4, Module 4, Article 1, pp. 1-52, 12-15-08 [copyright by authors]

activities. If the fears include most social situations, the disorder might be specified as generalized social phobia. Social phobia is one of the most common mental disorders with estimates of lifetime prevalence based on epidemiological studies in most Western Countries ranging from 7-13\% (Furmark, 2002). However, the figures vary considerably in different studies; probably mainly due to different cut-off lines for clinical caseness, since the required degree of distress or functional impairment is not specified in the diagnostic systems. A new, very large epidemiological study in 10 different European countries found a lifetime prevalence estimate for social phobia of only $2.4 \%$ (Alonso et al., 2004). Most often, the disorder starts in the adolescence period and generally it runs a chronic course (Keller, 2003). It is associated with deterioration in education, work, and social relationships as well as with comorbid mental disorders, especially other anxiety disorders, depression, alcohol abuse and personality disorder. Social phobia is generally found to have the highest degree of comorbid personality disorders among the anxiety disorders (Dyck et al., 2001; Sanderson, Wetzler, Beck \& Betz , 1994). It is estimated that only about 5-10\% among persons with social phobia seeks treatment for their condition and, if they do, they do so, on average, more than 15 years after its appearance (Keller, 2003).

\section{B. Cognitive Behavioral Therapy Models for Treating Social Phobia}

Cognitive behavioral therapy (CBT) is the empirically most supported psychological treatment for social phobia (Rodabaugh, Holaway \& Heimberg, 2004). CBT leads to clinically meaningful change for clients with social phobia with controlled or uncontrolled effect sizes, (as defined by Cohen's [1988] $d$ statistic) of around .80, i.e., a clinically meaningful effect, although most clients have residual social phobic problems after treatment (Rodabaugh et al., 2004). Controlled studies have mostly used wait-list control, and the fact that controlled between-group and uncontrolled pre-post effect sizes are of the same magnitude illustrates that there is little spontaneous remission in social phobia. One meta-analysis (Taylor, 1996) actually found a small, insignificant negative pre-post effect size for social phobia wait-list groups. The outcome of CBT for social phobia is in line with treatment of the disorder with medications (Davidson et al., 2004; Heimberg et al., 1998), but with more durable effects for CBT (Liebowitz et al., 1999).

The two most well-known treatment programs for social phobia are Heimberg's cognitive behavioral group treatment (Heimberg \& Becker, 2001), and Clark's (1997; Clark \& Wells, $1995)$ individual cognitive therapy. The two treatments are based on similar models of social phobia underlining the importance of negative automatic thoughts in social situations, a negative conception of self as presented to other people, avoidance and escape behaviors, including socalled "safety behaviours." These latter are dysfunctional coping strategies aimed at reducing anxiety or feared consequences of anxiety in the feared situations, such as hiding blushing with a scarf, over-preparing a speech, or avoiding eye-contact. (For an adaptation of the Clark and Wells program for a group setting, which is illustrated in a detailed case study, see Edwards \& Kannan, 2006).

The two treatment packages also include many of the same ingredients with a focus on cognitive restructuring (i.e., analysis and change of negative thoughts) and exposure to social situations. Clark more heavily than Heimberg stresses the importance of the clients's 
A Novel Group Therapeutic Format in Cognitive Behavioral Treatment for Clients with Social

Phobia in a Training Setting: A Case Study of One Treatment Group with Nine Clients

E. Hougaard, S.S. Madsen, L.M. Hansen, M. Jensen, G.S. Katborg,

L. Morsaa, M. Pedersen, S.M. Pedersen, \& J. Piet

Pragmatic Case Studies in Psychotherapy, http://pcsp.libraries.rutgers.edu

Volume 4, Module 4, Article 1, pp. 1-52, 12-15-08 [copyright by authors]

understanding of their individual "models of social phobia," their learning to focus outwards in social situations (to combat self-focused attention), avoiding safety behaviors, and correction of a negative conceptions of the self as a social object via video-feedback. Heimberg's treatment program, on the other hand, focuses more on repeated exposure exercises via role-playing in the therapy group. Clark's cognitive therapy has achieved remarkable results in some recent studies (e.g., Clark et al., 2006; Mörtberg, Clark, Sundin, Wisted \& Åberg, 2006; Stangier, Heidenreich, Peitz, Lauterbach \& Clark., 2003). Based on comparisons of pre-post effect sizes from recent studies Rodabaugh et al. (2004), however, suggest that the two treatment programs achieve comparable outcomes.

Most programs of CBT for social phobia consist of 12-15 weekly sessions. More intensive treatment programs have, however, also been tried out, e.g., a 41-hour program over a period of three weeks (Mörtberg, Clark et al., 2006; Mörtberg, Karlsson, Fyring \& Sundin 2006).

\section{Differences in Treatment Outcome for Individual Clients}

Generally, social phobic clients differ widely on personality trait (Rapee \& Spence, 2004) as well as on outcomes of treatment (Rodebaugh et al., 2004). Client pre-treatment characteristics might account for a large part of the differences in therapeutic outcomes, but the empirical literature has uncovered surprisingly few prognostic client variables, except that clients who begin treatment at a higher level of psychopathology also tend to function at a higher level of psychopathology after treatment, although the degree of change is not necessarily lower among severe cases (Rodebaugh et al., 2004). Patterns of relevant prognostic client variables might be highly complex and idiographic with very large samples needed for investigating such variables in quantitative research. It has been suggested (e.g. by Edwards, Dattilio \& Bromley, 2004) that systematic case studies are better suited for investigating the complex idiographic patterns of client prognostic variables.

The high degree of individuality might also be a limitation for generalizing from aggregated case studies if the aim is to establish general laws as a basis for so-called "rule-based reasoning." As noted above in the section on methods, case studies can, however, also function as prototypes in "case-based reasoning".

\section{The Treatment Program at the Aarhus Clinic}

The treatment program at the Anxiety Clinic at the Department of Psychology is based on a treatment schedule worked out at the Clinic for Anxiety Disorders at the University Psychiatric Hospital of Aarhus. The "Aarhus program" is described in a manual of CBT for panic disorder and social phobia designed for clients and therapists (Hougaard, 2006). With regard to social phobia, it is mostly inspired by the work of Clark (1997). The clients borrow a copy of the manual during the treatment period so that they can read about their disorder and its treatment. An intensive 3-week treatment program for panic disorder has been worked out and tested at the Anxiety Clinic at the Psychiatric Hospital (Johansen, Spindler, Arendt, Hougaard \& Rosenberg, submitted). The special treatment program for social phobia in this study was, however, developed at the Anxiety Clinic at the Psychological Department. 
A Novel Group Therapeutic Format in Cognitive Behavioral Treatment for Clients with Social

Phobia in a Training Setting: A Case Study of One Treatment Group with Nine Clients

E. Hougaard, S.S. Madsen, L.M. Hansen, M. Jensen, G.S. Katborg,

L. Morsaa, M. Pedersen, S.M. Pedersen, \& J. Piet

Pragmatic Case Studies in Psychotherapy, http://pcsp.libraries.rutgers.edu

Volume 4, Module 4, Article 1, pp. 1-52, 12-15-08 [copyright by authors]

The format of the program is outlined in Table 1 . As can be seen, in the beginning of the program students offer individual treatment for 2-4 sessions. The rationale for this is threefold: to get more information on individual clients (e.g., a problem-list and a case-formulation), to socialize the students into the therapist role, and to establish a therapeutic alliance to support client attendance at the intensive group-week.

The program uses components from Clark's (1997) cognitive therapy in the form of conceptualizing individualized models of clients' social phobia, teaching clients to focus outwards and avoid safety behavior, and making behavioral experiments with video-feedback. Some of the group role-playing exercises are inspired by Heimberg's group CBT (Heimberg \& Becker, 2001).

The intensive workshop is designed as a type of flooding experience, with maximum anxiety at the start of the first day. In spite of this high level of anxiety, all the clients turned up for all sessions except for one who had to be absent one day because of a job-seeking arrangement. All the clients were able to perform their individualized exposure exercises in front of the whole group during days three and four. There are examples of these exposure exercises in the individual case vignettes, in section 4-7 below.

The following 6 weekly group therapy sessions in smaller groups of 4 students and 4-5 clients are intended to help clients to use their learned skills in their everyday lives outside therapy. For students it is an opportunity to be more acquainted with group therapy, to learn from other students and to follow more clients for a longer period than would be possible if they only provided individual therapy.

The individual therapy after group treatment is, mostly, for clients with more serious problems and/or characterological problems. The treatment here often focuses more on personality in the form of "schema focused" CBT (Beck \& Freeman, 2004; Young, Klosko \& Weishaar, 2003).

The program is designed to be administered by student therapists who are mostly totally inexperienced in giving psychotherapy. This was true for all but two in the present study. The supervisors are required to be certified clinical psychologists. In the present study, one of the psychologists had more than 10 years of experience with CBT for anxiety disorders, and the other had two years of such experience.

\section{4-7 ${ }^{1}$. CASE INFORMATION, COURSE OF TREATMENT, AND THERAPY MONITORING FOR THE NINE CLIENTS IN THE GROUP}

As context to the discussion of the individual clients, each client's performance on the six standardized measures of psychopathology at different points during the therapy are presented in

\footnotetext{
${ }^{1}$ This section is numbered "4-7" to indicate its parallel to sections 4-7 of a typical PCSP case study-specifically, "4. Assessment of the Client's Problems, Goals, Strengths, and History"; "5. Formulation and Treatment Plan";

"6. Course of Therapy"; and "7. Therapy Monitoring and Use of Feedback Information."
} 
A Novel Group Therapeutic Format in Cognitive Behavioral Treatment for Clients with Social

Phobia in a Training Setting: A Case Study of One Treatment Group with Nine Clients

E. Hougaard, S.S. Madsen, L.M. Hansen, M. Jensen, G.S. Katborg,

L. Morsaa, M. Pedersen, S.M. Pedersen, \& J. Piet

Pragmatic Case Studies in Psychotherapy, http://pcsp.libraries.rutgers.edu

Volume 4, Module 4, Article 1, pp. 1-52, 12-15-08 [copyright by authors]

Tables 3A-3I. In addition, Figures 2A to 2I present each client's ratings during the intensive group-week on the Evaluation of Social Phobia measure (Appendix A). The individual case descriptions presented below are structured according to: a) presenting picture, b) history, c) course of treatment, and d) response to therapy. The clients are placed alphabetically within their outcome category as determined by the CGI rating at follow-up.

\section{Individual Clients Who Were Very Much improved: Niels, Vera}

\section{$\underline{1 .}$ Niels}

a. Presenting picture. Niels was a university student in his mid-twenties. His diagnoses were recurrent major depression, panic disorder with mild agoraphobia, and generalized social phobia. His social anxiety had been longstanding, and he himself thought it to be his primary problem. Outwardly, he appeared active and extroverted. Despite his depression, he was able to join some social activities and follow courses at the university, although he skipped many lectures. At the time of assessment Niels was highly disturbed and distressed as can be seen from his very high scores on all scales, including the SCID II-Q (see Table 2 and 3A).

b. History. Niels had had a rather traumatic childhood. His parents were divorced and, thereafter, his mother developed severe depression that never fully seemed to remit. Niels felt that he often had to take care of his mother. His biological father died when Niels was in his early teens. He experienced difficult relationships with several stepfathers. In his teenage period he had his first depressive episode. Shortly before his application for treatment at the clinic he and his girlfriend broke up - a break he described not so much as a loss but as yet another example of personal failure.

Niels had been on and off antidepressant treatment starting back in 2002. Just prior to application for treatment his psychiatrist had changed medication from mirtazapine (a new, atypical antidepressant) to the SSRI escitalopram (20 mg per day). He had also had a short course (6 sessions) of CBT with a psychologist.

c. Course of treatment. Prior to the intensive group-week Niels had only two individual sessions (due to late inclusion), and, thereafter, he attended 4 (out of the 6) weekly group sessions followed by 17 individual sessions. His exposure exercises in the intensive treatment week consisted of oral presentations with writing on the whiteboard, holding a paper with notes and drinking water in front of the whole group, thus clearly showing his shaking tendency to the audience. One of his presentations dealt with his own history; a topic he himself suggested because of his general avoidance of disclosing personal information, and thereby his weakness, to other people. His fear of shaking when drinking or eating in front of others was confronted the last two days by letting him sit in the circle of people with a glass of water. In the following weekly group therapy he socially exposed himself by making daily phone calls (which he feared) and by experiments with small disclosures of personal matters in conversations with others. In order to help him with his depressive agitation and rumination he was taught some mindfulness exercises. 
A Novel Group Therapeutic Format in Cognitive Behavioral Treatment for Clients with Social

Phobia in a Training Setting: A Case Study of One Treatment Group with Nine Clients

E. Hougaard, S.S. Madsen, L.M. Hansen, M. Jensen, G.S. Katborg,

L. Morsaa, M. Pedersen, S.M. Pedersen, \& J. Piet

Pragmatic Case Studies in Psychotherapy, http://pcsp.libraries.rutgers.edu

Volume 4, Module 4, Article 1, pp. 1-52, 12-15-08 [copyright by authors]

The following, rather extensive, individual therapy (17 sessions) focused more on his dysfunctional personal attitudes, e.g. his tendency to perfectionism in his work, leisure and social life. Here he learned better to accept himself, including his weak spots, and to share his problems and sad and anxious feelings with his family, close friends and new girlfriend. Thus, he no longer needed always to appear infallible, happy, energetic, and likable, which made his life much easier.

d. Response to therapy. After the group treatment program there were large declines on all symptomatic scales (see Table 3A). Niels was optimistic about his future, and stated that he "was able to live with his anxiety at that level." He still thought, however, that he "was not as well functioning as others." At the time of follow-up, after further individual treatment, he was within normal range on all scales, corresponding to a large and clinical significant change.

Niels was very enthusiastic about treatment. In his last session he described his change as "fabulous." At that time he had successfully completed his practicum, was no longer inhibited by anxiety in his social activities at work or in leisure, and he was much better at accepting himself without having to prove his worth all the time. His relationship with his new girlfriend was, so far, his most harmonious one. He had stopped treatment with antidepressant medication. He was judged "very much improved" on the CGI.

Niels' individualized scales declined consistently during the intensive group-week (see Figure 2A). In relation to the group therapy he stressed the importance of the video-feedback from his exposure presentations and the feedback from the other group members challenging his conception of himself as socially incompetent. He rather quickly understood the principles of CBT for social phobia, and throughout treatment he very keenly and consistently used exposure to confront interpersonal problems in his day-to-day living. Thus, he was a very dedicated and hard working client - perhaps having to prove his worth as a client too? As it can be seen from his self-report scales (Table 3A), he improved considerably during the period of individual therapy after group treatment so he probably profited from the schema-focused approach in this part of the therapy.

\section{Vera}

a. Presenting picture. Vera was in her forties, worked as a kindergarten teacher and lived with her second husband and three children. Her social phobia was limited to achievement situations, especially situations where she had to say something in front of a group, but also when she unexpectedly met old friends. She was afraid that others might find her incompetent and judge her negatively because of her anxiety, which she thought was highly visible because of her blushing tendency. She tried to hide her blushing with hair hanging down, make-up and a scarf ("safety behavior"). Vera scored rather low prior to therapy on the six symptomatic scales (see Table 3B) and on the SCID-II-Q (see Table 2), probably because her problems were focused and situation-specific. However, they were distressing and impaired her social functioning, especially at work where she was anxious about meetings and talking with parents. Several years ago she declined a promotion at work because of her anxiety. 
A Novel Group Therapeutic Format in Cognitive Behavioral Treatment for Clients with Social

Phobia in a Training Setting: A Case Study of One Treatment Group with Nine Clients

E. Hougaard, S.S. Madsen, L.M. Hansen, M. Jensen, G.S. Katborg,

L. Morsaa, M. Pedersen, S.M. Pedersen, \& J. Piet

Pragmatic Case Studies in Psychotherapy, http://pcsp.libraries.rutgers.edu

Volume 4, Module 4, Article 1, pp. 1-52, 12-15-08 [copyright by authors]

b. History. Vera grew up in a rather conventional family, within which she learned not to assert herself but rather to accommodate to other people's opinions. When she was very young she married an older man who dominated and criticized her. The marriage lasted for about ten years and it further contributed to undermine her self-confidence.

Vera's social phobia started about ten years ago when she was head of an after-school recreation center. She was stressed by conflicts with colleagues and felt lonely after the divorce from her first husband. She experienced some unexpected panic attacks at that time which might have contributed to her social phobia. Vera did not, however, seek treatment for her anxiety, and she had never before applied for psychological treatment.

c. Course of treatment. Vera had 4 individual sessions prior to the intensive weekprogram and 4 weekly group sessions in the following period. In the initial individual sessions there was a focus on Vera's blushing tendency and on her low self-esteem, which she attributed to her childhood and her relationship to her first husband. In the intensive group-week she talked about her blushing problem in the large group without wearing a scarf on the third day. Although she beforehand predicted that she would blush, the other group members noticed little blushing, and she herself could see no sign of blushing on the video, although she was sure she blushed somewhat. She was satisfied with her appearance on the video since she looked rather calm and succeeded in expressing what she wanted to say. The last day she talked about her relationship with her first husband in the small group of five clients.

In the following group therapy she worked with exposure and assertiveness tasks on her workplace.

d. Response to therapy. Vera showed statistically and clinically significant change on all scales after group therapy, and on all but two (BAI and BDI-II, still with low scores) at followup (see Table 3B). Vera was highly satisfied with her treatment and stated that she could now better "catch my negative thoughts before they catch me," that she "cares less about blushing because it does not mean that others think negatively about me," and "feels more free and happy in my daily living." She was now much better at actively joining the meetings at her work and felt less anxious when talking with parents. She was judged "very much improved" on the CGI.

Vera misunderstood the meaning of the individual scales and filled them out with different problems for the different sessions, and so her scores are not shown in Figure 2.

Vera thought that the mix of different therapy formats was useful for her. The intensive group-week especially contributed to reducing her fear of blushing because of exposure experiments with video-feedback. The following weekly group sessions were useful for transferring her insights from the group to problems at her workplace. The individual therapy gave her the opportunity to talk about some of her more personal experiences, such as her relationship with her family of origin and her first, intimate male partner. It helped her a lot to understand that her basic assumptions or "rules of living" - e.g., never to take chances or disagree with others - were based on her past experiences, and that she could work on changing them now when her situation was quite different 
A Novel Group Therapeutic Format in Cognitive Behavioral Treatment for Clients with Social

Phobia in a Training Setting: A Case Study of One Treatment Group with Nine Clients

E. Hougaard, S.S. Madsen, L.M. Hansen, M. Jensen, G.S. Katborg,

L. Morsaa, M. Pedersen, S.M. Pedersen, \& J. Piet

Pragmatic Case Studies in Psychotherapy, http://pcsp.libraries.rutgers.edu

Volume 4, Module 4, Article 1, pp. 1-52, 12-15-08 [copyright by authors]

\section{Individual Clients Who Were Much Improved: Ann, John, Mary, Peter}

\section{$\underline{\text { 3. Ann }}$}

a. Presenting picture. Ann was a 28-year-old woman who was living alone and worked in a shop. She was suffering from generalized social phobia and was highly preoccupied with her tendency to blush in social situations, which she found very embarrassing and tried to hide with make-up, scarves and letting her hair hang down. Blushing meant to her that she was "immature, weak, and incompetent". Although she was a pretty and charming woman, her life was highly restricted by her anxiety. For example, she did not dare to say anything in larger groups, she avoided most social arrangements, especially if they involved meeting new people, and had never had an intimate relationship with a man. Ann had low self-esteem and thought others would disdain her if they knew about her anxiety. Although Ann outwardly did not seem very disturbed, she achieved rather high scores on all scales, including the SCID-II-Q (see Tables 2 and $3 \mathrm{C}$ ).

b. History. Ann said that as a child she was very nervous, being afraid of a rather strict father. Her parents both had problems with anxiety or depression, and their relationship was strained. She did not, however, describe any social phobic problems until she was sixteen and away from home at a board-and-lodging, continuation school, where she suddenly blushed after giving a wrong answer in a Danish lesson. The stay at the school was very unpleasant for Ann.

Some years before she entered the treatment program at the Anxiety Clinic she had tried individual psychotherapy for ten sessions; and she had also tried SSRI (paroxetine and citalopram) administered by her general practitioner four years ago. Both treatments had no effect. Three years ago she participated in an intensive group treatment program at a private institution (a so-called "phobia school", a special Danish treatment organization) based on CBT principles with some effect.

c. Course of therapy. Ann's treatment at the Anxiety Clinic consisted of 3 individual sessions before, and one group and 7 individual sessions after the intensive week, i.e., altogether 11 sessions plus the intensive week-program (for practical reasons related to her work she only attended one of the planned 6 weekly group sessions following the intensive week). She already carried through some exposure exercises successfully in the period before the intensive week, e.g., talking with colleagues, and sitting close to a "scary" man "who could be expected to say anything."

In the intensive group-week she mostly feared blushing, which she thought would make others think she was ridiculous, weak and insecure. In her first exposure exercise in front of the whole group the third day she gave a presentation about the blushing reflex (based on information in the manual). The video-feedback and feedback from the other members of the group clearly disproved her prediction of how she would appear in the situation ("I will redden like a strawberry"). Actually, although she felt very anxious, unpleasant and warm in her face, her blushing was only slightly visible. One of the group members described her as "smiling and showing confidence ... with no signs of reddening." Among her alternative thoughts after 
A Novel Group Therapeutic Format in Cognitive Behavioral Treatment for Clients with Social

Phobia in a Training Setting: A Case Study of One Treatment Group with Nine Clients

E. Hougaard, S.S. Madsen, L.M. Hansen, M. Jensen, G.S. Katborg,

L. Morsaa, M. Pedersen, S.M. Pedersen, \& J. Piet

Pragmatic Case Studies in Psychotherapy, http://pcsp.libraries.rutgers.edu

Volume 4, Module 4, Article 1, pp. 1-52, 12-15-08 [copyright by authors]

cognitive restructuring were, "it's OK to blush," "blushing does not mean that I'm weak and insecure," and "I can say something in a group even though I'm nervous." On the last two days, inspired by Vera's example, she volunteered to experiment with putting her hair up before coming to the group. She had not dared to do this for several years, and it resulted in her experiencing anxiety at the maximum level of 10 . The anxiety declined considerably rather quickly and she was proud of braving her fear.

The last day of the intensive week she talked about how important acceptance from others had always been for her, and how it related to her experiences with an emotionally detached father. She stated that she now "by glimpses recognizes how foolish it is to be so critical about myself."

d. Response to therapy. According to the self-report scales Ann clearly profited from treatment, although there were clinical levels of residual anxiety and social phobic symptoms on all scales after therapy (see Table 3C). At follow-up there were some slight elevations on symptomatic scales compared to immediately after therapy, maybe due to stress related to her moving to a new town and starting a new job at that time.

Ann appreciated the treatment program. After treatment she told her therapist that she was now better able to accept her blushing tendency, renounce her safety behaviors (e.g., sometimes putting her hair up, rather than letting it hang over her face and neck), and was more socially active, although she still had not had any dating experiences. She stated that, "I have been better at accepting myself," and "I will no longer lull myself back into my negative way of thinking but dare to take risks and do something new." She was judged "much improved" on the CGI.

Ann only filled out individualized scales for the first three days of the intensive groupprogram and there were no clear changes on her scores (see Figure 2C). There was no phobic avoidance on her two most feared situations, "saying something in a group" and "eating in the canteen," since she was forced to brave these situations in the treatment. Her two most prominent safety behaviours, monitoring anxiety symptoms and letting her hair hang down to hide blushing, were top rated (i.e., 10 or 9) throughout the three days. As mentioned above, she renounced on this, last mentioned safety behaviour the last two days with no data on the scales. As important aspects in therapy, Ann stressed the being together with other people with similar problems, and the exposure exercises with video-feedback disproving her negative view of self from an outside observer's perspective.

\section{John}

a. Presenting picture. John was a young man in his early twenties who was referred from the psychiatric hospital, where he was diagnosed with social phobia and depression. A couple of years prior to treatment he dropped out, firstly from his apprenticeship and later from a course at a technical, upper-secondary school. At the time of applying for treatment he was living on social security benefits. Just before his referral he had dropped out from a limited-period job offer two hours a day because of his social anxiety. He spent most of his time at home in his 
A Novel Group Therapeutic Format in Cognitive Behavioral Treatment for Clients with Social

Phobia in a Training Setting: A Case Study of One Treatment Group with Nine Clients

E. Hougaard, S.S. Madsen, L.M. Hansen, M. Jensen, G.S. Katborg,

L. Morsaa, M. Pedersen, S.M. Pedersen, \& J. Piet

Pragmatic Case Studies in Psychotherapy, http://pcsp.libraries.rutgers.edu

Volume 4, Module 4, Article 1, pp. 1-52, 12-15-08 [copyright by authors]

apartment where he was living with his new girl friend. Except for a few close friends, he avoided most social situations, e.g., being in groups, eating in public places, talking with strangers or authorities, and making or answering phone calls. John scored rather high on all scales before therapy, including the SCID-II-Q (see Tables 2 and 3D).

b. History. John grew up in a home with an alcoholic mother and was always a shy boy. His social phobia, however, first started in his late teens as he attended technical school as part of his apprenticeship. At that time, he was diagnosed with a chronic health problem that made him feel different from others. A little later he suffered from serious panic attacks in social situations.

Two years ago, after dropping out from technical upper-secondary school, he was treated by his general practitioner with paroxetine ( $40 \mathrm{mg}$ pr. day), a treatment that is still going on. His referral for treatment was precipitated by his failing to take up an offer of temporary employment.

c. Course of treatment. The treatment consisted of 5 individual sessions prior to the intensive week-program, and, thereafter, 3 weekly group sessions and 9 individual sessions. John had been highly socially evasive and several times he had failed to turn up for appointments in his earlier contacts with the treatment system. Correspondingly, he was at first highly anxious in the initial sessions of individual therapy with visible shaking and sweating, and avoidance of eye contact. He learned the important lesson, however, that his anxiety gradually dropped during the individual sessions as well as from session to session. This helped him to understand one central principle of exposure, i.e., that anxiety declines after a while if you stay in the situation. He thereafter accepted some homework tasks, e.g., to go down town and do his shopping on his own.

When he appeared the first day of the intensive group-week, he was extremely anxious just to be present in the group, but determined to stay. At day four he expressed his lesson in the following way: "I know I can go through this, and if I stay long enough my anxiety will go down." Exposure exercises included reading a paragraph on social anxiety from the manual in front of the whole group and telling the group about himself and his life. On day four his level of anxiety had decreased considerably, and he was very proud of his successful presentations.

The following period - with at first weekly group therapy and later, further individual therapy - mostly focused on John's continued use of exposure tasks in his day-to-day living, e.g., in making phone calls, in joining social activities outside his home, and, late in the therapy course, in carrying through his limited-period job offer.

d. Response to therapy. According to the self-report scales John profited a great deal from therapy, with large changes and all scores within normal range at follow-up (see Table 3D). Most of his changes on the social phobia scales (SPS and SIAS) took place in the period of individual therapy when he completed his limited-period job offer (see Table 3D).

John was highly satisfied with his treatment, which, according to his own descriptions had made him less anxious and depressed with more energy and better sleep function. He no 
A Novel Group Therapeutic Format in Cognitive Behavioral Treatment for Clients with Social

Phobia in a Training Setting: A Case Study of One Treatment Group with Nine Clients

E. Hougaard, S.S. Madsen, L.M. Hansen, M. Jensen, G.S. Katborg,

L. Morsaa, M. Pedersen, S.M. Pedersen, \& J. Piet

Pragmatic Case Studies in Psychotherapy, http://pcsp.libraries.rutgers.edu

Volume 4, Module 4, Article 1, pp. 1-52, 12-15-08 [copyright by authors]

longer avoided any of his former feared social situations, although he still experienced some anxiety in the situations. By the end of therapy he had completed a half-time, three month temporary employment contract. He was looking for an unskilled job but was still not working. He was judged "much improved" on the CGI, but not top-rated because he was still reluctant to seek work or education at the time of treatment ending.

One year after he finished therapy he was referred to the anxiety clinic at the psychiatric hospital for an evaluation of his employability in connection with a new job offer from the local authorities. The assessing psychologist found there was no clinical diagnosis, and John himself stated that he was doing fine and looked forward to start on his new job. We do not know why a whole year passed before John received a new job offer, since such a policy with regard to unemployed young people is rather unusual in Denmark.

John's individual scales in the intensive group-week show impressive and steady declines on all measures. There were zero scores on phobias already the first day because he had to confront his major fears (i.e., being in large groups, eating with unfamiliar people, and saying something in a group) with exposure in the group (see Figure 2D).

After treatment John especially emphasized the intensive week-program, which he described as "barrier-breaking." His success experiences here were probably of utmost importance to breaking his longstanding, self-defeating social avoidance pattern. The following group and individual therapy seemed to have helped him with getting back on track in his social rehabilitation.

\section{Mary}

a. Presenting picture. Mary was referred to the clinic from the Student Counselling Centre. She was a university student in her mid-twenties living together with her boyfriend in a steady relationship for several years. She did not have many acquaintances although a few good friends. Mary was permanently sad and anxious with numerous worries and ruminations, and she was very strained and reserved in her social relationships. Her diagnoses were generalized social phobia, major depression, and dysthymia. At the time of assessment she overate and over-slept, symptoms usually connected with atypical depression. She scored very high on the symptom scales, including the BDI-II (40), as well as on the SCID-II-Q (see Tables 2 and 3E), with a probable diagnosis of avoidant personality disorder. Her specific reason for application for treatment was the experience of severe problems with giving presentations in class, which made it difficult for her to attend class at all.

b. History. From early childhood Mary was a shy girl. Both parents were depressed and she, as the oldest of four siblings, was responsible for many daily tasks in the family. Her parents were preoccupied with keeping up appearances, and Mary felt responsible for protecting them. She did well in school but never got any recognition for her achievements. As a teenager she was teased and excluded from her group of peers. In her study at the university she felt more and more isolated among her fellow students; and after a "very awful" presentation where she experienced "paralysing anxiety with trembling and mental blackout," she started to skip classes. 
A Novel Group Therapeutic Format in Cognitive Behavioral Treatment for Clients with Social

Phobia in a Training Setting: A Case Study of One Treatment Group with Nine Clients

E. Hougaard, S.S. Madsen, L.M. Hansen, M. Jensen, G.S. Katborg,

L. Morsaa, M. Pedersen, S.M. Pedersen, \& J. Piet

Pragmatic Case Studies in Psychotherapy, http://pcsp.libraries.rutgers.edu

Volume 4, Module 4, Article 1, pp. 1-52, 12-15-08 [copyright by authors]

Prior to contacting the Student Counselling Centre, she had never applied for help for her psychological problems.

c. Course of treatment. Mary had 4 individual sessions prior to the intensive group-week; 2 weekly group sessions in the follow-up period (with several cancellations because of examinations); and 6 individual sessions after a two months' break due to summer holiday. She had an oral presentation in one of her educational courses in the period of individual therapy prior to the intensive group week, which was prepared beforehand as a behavioral experiment. The presentation went better than expected, thus strengthening her morale somewhat before the intensive treatment week. The work here also focused on oral presentations. The third day she gave a presentation in front of the whole group on her educational background without safety behaviors (over-preparation, chewing gum, talking fast, and wearing a necklace), and with instruction to make at least one artificial long pause. Before the experiment, she feared she would appear stiff and lifeless, be highly anxious (at level 10), blush, and lose the thread of her presentation and talk nonsense. The feedback from the audience was, however, positive, and after viewing the videotape she commented that her blushing was not highly visible, and that she could see that she smiled and made appropriate gestures. Among her alternative thoughts after the experiment were, "I can pick up the thread again, even if I pause," "nervousness is not the same as stupidity." and "I can make an okay presentation even though I am nervous." The fifth day she mentioned basic beliefs about her need for acceptance from others and her perfectionism in performance situations. She realized that these beliefs were part of her problem, and promised herself to reevaluate them.

The individual sessions after the group program dealt with her ambivalent feelings toward her family of origin for which she felt very guilty. This part of the therapeutic work was highly emotionally charged, but she found it relieving to tell about her experiences and feelings, which she had not shared with anyone before.

d. Response to therapy. According to the scales shown in Table 3E, Mary was better after therapy and at follow-up than she was before treatment, with large changes on the BDI-II and SIAS. All the end-state scale scores were, however, still in the clinical range.

Mary was very satisfied with treatment, and from a clinical point of view, she also seemed to have profited considerably. After treatment she was much better in giving presentations in school and no longer skipped classes because of anxiety. In fact, she actually signed up voluntarily for presentation tasks. She applied for and got a leisure-time job as a telephone interviewer whereas before treatment she was highly fearful of making phone calls. She was also able to accept herself better and to challenge her belief that she was responsible for protecting her mother and father. As a result she was able to disentangle herself from an overly involved relationship with them. However, she still continually worried about very many matters. Although she still had serious problems, she attained her main objectives of treatment, being able to attend class and to give oral presentations. She was judged "much improved" on the CGI. 
A Novel Group Therapeutic Format in Cognitive Behavioral Treatment for Clients with Social

Phobia in a Training Setting: A Case Study of One Treatment Group with Nine Clients

E. Hougaard, S.S. Madsen, L.M. Hansen, M. Jensen, G.S. Katborg,

L. Morsaa, M. Pedersen, S.M. Pedersen, \& J. Piet

Pragmatic Case Studies in Psychotherapy, http://pcsp.libraries.rutgers.edu

Volume 4, Module 4, Article 1, pp. 1-52, 12-15-08 [copyright by authors]

Mary's individual scales from the intensive group-week for the first four days show an interesting pattern with declines in phobic avoidance, safety behaviors, and negative thoughts, but a simultaneous rise in anxiety, probably due to worries about the next day's exposure exercises (see Figure 2E).

Mary thought she profited especially from exposure presentations in the intensive groupweek with video-feedback as well as from being together with others with similar problems. Here she learned that anxiety is not necessarily highly visible outwardly and that it is possible to perform even with considerable anxiety. Being aware of her self-focusing tendency and learning to focus outwards in the feared situations were also very useful for her, especially in oral presentation situations. She also mentioned that the cognitive strategies had helped her to spot and correct her negative automatic thoughts.

\section{$\underline{6 .}$ Peter}

a. Presenting picture. Peter was in his late twenties and a student of engineering at the university. He was married, and he and his wife had a child. Peter suffered from specific social phobia with a special focus on achievement situations, e.g. oral examinations, oral presentations and speeches. In such situations he was afraid of making stupid mistakes, of appearing stiff and boring to the audience, or, ultimately, of fainting, which actually had happened on some occasions (an unusual, although not exceptional response among persons with social phobia). He prepared speeches meticulously with everything written down on paper and feared being interrupted or confused and losing the thread of his talk. When in the feared situations, he monitored his symptoms of anxiety to evaluate the risk of fainting. When he applied for treatment, he was especially concerned with fear of fainting when he was going to defend his thesis at his final examination, or when he would present the results for the company where his study had taken place and where he would apply for a job. He was also somewhat inhibited in groups or with authorities, with a tendency to easily blush. Although he was generally well functioning with a diagnosis of specific social phobia, he also scored rather high on the SIAS, which measures interaction anxiety, and on the SCID-II-Q (see Tables 2 and 3F). Among his three most unpleasant negative thoughts in feared situations he mentioned, "I am not good enough," "I lose the thread/black-out," and "I am weak and cannot really join the group."

b. History. Peter grew up in a strongly religious family with social restrictions, which made him rather isolated from peers in his youth. His specific fear of fainting started in an examination situation in primary school where he actually fainted. On a few occasions he fainted when giving an oral presentation in the School of Engineering. Through his general practitioner he had tried medical treatment with benzodiazepines and beta-blockers without results.

c. Course of treatment. Prior to the intensive group-week Peter had 4 individual sessions, attended two of the following weekly group-sessions, and then went on holiday abroad. During the intensive group-week Peter gave short speeches on technical topics, which he expected to be quite boring to this audience, and he role-played a job-evaluation conversation. He was instructed to focus outwards instead of monitoring his anxiety symptoms and to make small pauses in his presentations. His last presentation was staged as a role-play of a situation where he 
A Novel Group Therapeutic Format in Cognitive Behavioral Treatment for Clients with Social

Phobia in a Training Setting: A Case Study of One Treatment Group with Nine Clients

E. Hougaard, S.S. Madsen, L.M. Hansen, M. Jensen, G.S. Katborg,

L. Morsaa, M. Pedersen, S.M. Pedersen, \& J. Piet

Pragmatic Case Studies in Psychotherapy, http://pcsp.libraries.rutgers.edu

Volume 4, Module 4, Article 1, pp. 1-52, 12-15-08 [copyright by authors]

had to give a report on some research results in front of a panel of executives (a task he actually had to perform in the near future). Peter's performances were all very fluent and eloquent, but he did experience high anxiety and, in particular, worries about fainting. He learned, however, that he was able to manage his anxiety even during intensive exposure, and he appreciated the positive feedback on his performance from the other group members. The video-feedback convinced him that his self-image as a stiff and boring public speaker was distorted.

During the week Peter participated quite openly and actively in the group with positive contacts with the other group members. This experience probably somewhat challenged his beliefs about not fitting in and his general strategy of being very reserved with regards to emotions and personal problems.

d. Response to therapy. Peter did not hand in scales after therapy, first because he was away, and then, probably, because he was too busy in his new job. Six months after treatment, however, we received follow-up scales from him with two different dates separated by about two months (see Table 3F). There were some declines on SPS, SCL-90 and IIP-C, but none on the SIAS.

Peter was highly satisfied with treatment. After treatment he was able to present successfully on several occasions, including the oral presentation at the company (where he was later hired), giving a speech at a party with several hundred guests and at the defence of his thesis. He stated that his fear of presentations had declined, although he still had negative thoughts about fainting. He was judged "much improved" on the CGI since he achieved his main treatment objectives, being able to give oral presentations with only minor anxiety. We had no personal contact with Peter at follow-up. As Peter left therapy shortly after the intensive groupweek, there was little time for further therapeutic work with his interaction anxiety and personal attitudes, which might otherwise have been helpful for him.

Peter's individualized scales from the intensive group-week show a steady decline except for a high peak on anxiety before the third day when he knew he was going to give an oral presentation in front of the large group the next day (see Figure 2F).

Peter especially stressed the importance of his exposure to giving presentations. Here he learned to focus outwards instead of monitoring his anxiety symptoms and to allow himself to make small pauses to get back on track, and his distorted self-image was challenged by feedback from the other group members and his own viewing of the video.

\section{Individual Client Who Was Minimally Improved: Mona}

\section{Mona}

a. Presenting picture. Mona was in her late twenties and lived with her boyfriend. Earlier, she had different unskilled jobs, but at the time of application for treatment she was unemployed and reluctant to seek new jobs. Mona was suffering from specific social phobia with a fear of saying something in a group and a fear of disagreeing with others. She was not highly 
A Novel Group Therapeutic Format in Cognitive Behavioral Treatment for Clients with Social

Phobia in a Training Setting: A Case Study of One Treatment Group with Nine Clients

E. Hougaard, S.S. Madsen, L.M. Hansen, M. Jensen, G.S. Katborg,

L. Morsaa, M. Pedersen, S.M. Pedersen, \& J. Piet

Pragmatic Case Studies in Psychotherapy, http://pcsp.libraries.rutgers.edu

Volume 4, Module 4, Article 1, pp. 1-52, 12-15-08 [copyright by authors]

conscientious with regard to social duties and she very easily felt resentful. She had many interpersonal difficulties, including conflicts with her mother and her new family-in-law. Mona scored very high on the SCID-II-Q, especially on avoidant and dependent, but also on other disordered personality traits, corresponding to the clinical impression that her problems were related to her personality (see Table 2).

b. History. According to Mona she was always a shy and inhibited child. Her parents were divorced in her childhood, and she stayed with her overprotecting and dominating mother. In primary school she was severely teased and had conflicts with her peers.

c. Course of treatment. Mona had 3 individual sessions prior to the intensive group-week and 4 weekly group-sessions, as well as 4 individual sessions thereafter. Then, she unexpectedly dropped out of therapy.

In the intensive group-week Mona gave short presentations in front of the whole group on herself and her current life circumstances. She was very reluctant to undertake these exposure assignments, but did not outwardly show many signs of anxiety during the presentations. She was dissatisfied with her own performance and at first refused to watch the videotape. When she was finally persuaded to do so, she judged her performance and general appearance as reprehensible, since her behavior did not match her own perfectionist standards. The most notable intervention with Mona during the intensive group therapy was a role-play focusing on her conflicts with her mother, which took place on Mona's own suggestion. She became highly emotionally involved during the role-play and had to be supported by her individual therapist. Mona experienced this exercise as very valuable, although her individual therapist considered it mere catharsis. She explained her problems as caused by her family of origin where she had always felt dominated, criticized and misunderstood.

The unexpected break appeared after Mona had mentioned that the social security office was putting pressure on her to apply for a job, and that her boyfriend had threatened to break up because of little change in her ability to manage her emotions and take responsibility for her life. Several attempts to contact her again were unsuccessful. Her therapist thought that she might have been angry because treatment had not helped her to change enough to please her boyfriend. This would have been consistent with her tendency to dichotomous, "black-or-white" thinking in interpersonal situations.

d. Response to therapy. Mona had a large change after therapy on the social phobia scales, i.e., SPS and SIAS (see Table 3G). From a clinical point of view, however, her personality problems clearly overshadowed her social phobia. Since she did not attend follow-up, we have no data on personality problems after treatment and also no knowledge of any possible durable symptomatic change.

Mona was very enthusiastic about treatment after the intensive group-week. She said that other people, including her boyfriend and his family, had commented on how different she appeared as a consequence of treatment. Apparently there was some decline in socially phobic behavior immediately after therapy, but she did not seem to have changed with regard to her 
A Novel Group Therapeutic Format in Cognitive Behavioral Treatment for Clients with Social

Phobia in a Training Setting: A Case Study of One Treatment Group with Nine Clients

E. Hougaard, S.S. Madsen, L.M. Hansen, M. Jensen, G.S. Katborg,

L. Morsaa, M. Pedersen, S.M. Pedersen, \& J. Piet

Pragmatic Case Studies in Psychotherapy, http://pcsp.libraries.rutgers.edu

Volume 4, Module 4, Article 1, pp. 1-52, 12-15-08 [copyright by authors]

attitudes toward responsibility or job seeking. On the CGI she was judged "minimally improved" after treatment because she did show some immediate symptomatic change, even though most of her interpersonal problems seemed the same as before treatment.

From Figure $2 \mathrm{G}$ it can be seen that Mona's individual scales in the intensive group-week impressively declined with almost no symptomatic scores at the end of the week, corresponding to her large change on the two social phobia scales, SPS and SIAS, after the weekly group treatment (see Table 3G). The large symptomatic changes on the scales seemed somewhat paradoxical compared with the clinical impression of rather little change, at least with regard to her personal traits and attitudes. Her post-treatment scale scores might have been influenced by her enthusiasm immediately after therapy - which would also be in line with her dichotomizing thought style. Her personality problems were, probably, an obstacle to a more satisfactory therapeutic response in this form of treatment.

\section{Individual Clients Who Showed No Change: Cecilia, Laila}

\section{Cecilia}

Presenting picture. Cecilia was 28 years old, married, and pregnant. She was studying to become a social worker. She had a rather circumscribed, specific social phobia, mostly related to giving presentations in her classes. She described her main problem as achievement anxiety, fear of not being able to live up to her own standards. Except for her score about one standard deviation above the normal mean on SPS, a scale especially relevant for specific social phobia, her scale scores were all rather low (see Tables 2 and $3 \mathrm{H}$ ).

History. Cecilia grew up as the only child in a family with a rather authoritarian father and a submissive and overprotecting mother. According to her, her father was a man of high standards for himself as well as for others. As a child she felt close to him when she behaved cleverly. Otherwise, he seemed rather detached. She thought her problems were related to her wish to live up to her father's expectations. Her social phobia started in high school where she was not able to achieve the high grades she used to get in primary school.

c. Course of treatment. Cecilia had two individual sessions prior to the intensive weekcourse (she was rather lately included) and, thereafter, she attended only one group session because of examinations and vacation. In the intensive group-week her first exposure task in front of the whole group consisted of a theoretical presentation on the social phobia model with instructions to attempt to lower her level of aspiration and to make at least one intended mistake (this last requirement was not met). The focus was agreed to be on the mode of presentation and not on its content. Cecilia was not satisfied with her achievement; she thought she talked too fast in a "feverish" manner and made odd gestures. Feed-back from the other members of the group made her, however, hesitatingly accept that her mode of presentation was "reasonably good enough."

d. Response to therapy. There was statistically and marginally clinically significant change on the SPS after treatment (see Table $3 \mathrm{H}$ ). There was no change on other scales, but 
A Novel Group Therapeutic Format in Cognitive Behavioral Treatment for Clients with Social

Phobia in a Training Setting: A Case Study of One Treatment Group with Nine Clients

E. Hougaard, S.S. Madsen, L.M. Hansen, M. Jensen, G.S. Katborg,

L. Morsaa, M. Pedersen, S.M. Pedersen, \& J. Piet

Pragmatic Case Studies in Psychotherapy, http://pcsp.libraries.rutgers.edu

Volume 4, Module 4, Article 1, pp. 1-52, 12-15-08 [copyright by authors]

Cecilia's scores had been low before treatment. There were no follow-up data because of the delivery of her child.

Based on the clinical information, there did not seem to be much change on her fear of giving presentations after treatment. We judged "no change" on the CGI. Cecilia only filled out individualized scales for three days in the intensive group-week, and they show no clear pattern (see Figure 2H). Apparently her belief in her negative thoughts about not being able to present in a satisfactory way was strong from start to the end of the week.

Cecilia was somewhat critical of cognitive behavioral therapy, which she knew about beforehand from her social work studies. She said that her exposure presentations in the group were not really meaningful because members of the audience were not qualified to evaluate her achievement. An individual treatment course focusing on her high inner standards might have been more suitable for her, but she had to stop therapy because of the delivery of her baby.

9. Laila

a. Presenting picture. Laila was a 53-year-old woman from the Middle East who escaped from a totalitarian regime about 20 years ago and together with her family attained status as refugees in Denmark. She and her husband were employed, Laila as an educational worker, and they had four children. In her letter of application for treatment, she wrote about experiences of anxiety and depression associated with traumatic memories of her escape from the regime through the mountains in snowy weather when pregnant with her second child. Several cues would trigger memories of these events, such as snowy weather, going into the cellar at her apartment house, being alone with strangers in a bus, or taking a bath when alone at home. At these times she sometimes had thoughts of being raped, something which the police had threatened her with when interrogating her. She also mentioned problems of talking in front of groups at work, partly related to her different cultural background. In such situations she had self-critical thoughts concerning the quality of her language, what Danish people might think of her cultural background, and the like.

Laila was not given any formal psychiatric diagnosis but only a primary sub-threshold diagnosis of PTSD and a secondary sub-threshold diagnosis of social phobia. In therapy it turned out that her most urgent problem was severe conflicts with her husband after their daughter's marriage that he opposed, which was leading Laila seriously to consider divorce. Her husband also had chronic psychological difficulties resulting from the traumatic experiences associated with his opposition to and flight from the regime in his native country. Laila thought he was in need of psychotherapy, even more than she was, but that he would never consider such a treatment since he thought it was only "for lunatics" - a view that certainly did not support Laila's own therapy, although it should be noted that his view was rather typical for men from his country.

b. History. The inexperienced therapist found it difficult to direct Laila into providing the information needed for a full clinical history, because she spoke at great length about her frightening experiences while escaping as well as about her present problems with her husband. 
A Novel Group Therapeutic Format in Cognitive Behavioral Treatment for Clients with Social

Phobia in a Training Setting: A Case Study of One Treatment Group with Nine Clients

E. Hougaard, S.S. Madsen, L.M. Hansen, M. Jensen, G.S. Katborg,

L. Morsaa, M. Pedersen, S.M. Pedersen, \& J. Piet

Pragmatic Case Studies in Psychotherapy, http://pcsp.libraries.rutgers.edu

Volume 4, Module 4, Article 1, pp. 1-52, 12-15-08 [copyright by authors]

Both Laila, her family of origin, and her husband had been active political opponents of the regime in their native country, and she remembered being questioned and threatened by the police on several occasions.

c. Course of treatment. Laila was offered 4 individual therapeutic sessions before the intensive group-week and, thereafter, she joined 5 weekly group sessions. The individual sessions prior to the intensive group week, all about $1 \frac{1}{2}$ hours of duration, were devoted to an emotionally charged retelling of her traumatic past and the problems in her marriage, highly directed by Laila's own immediate needs with little opportunity for therapeutic direction, focusing, or processing.

Laila was not socialized into the cognitive methods in individual therapy prior to the intensive group-week, but in the group-week she rather quickly understood the therapeutic principles. She arrived 5 minutes late at the first session, and chose this episode as the target of her first analysis of negative thoughts. She felt highly anxious in the situation (level 9-10) with thoughts like, "they think I don't care about therapy, that I am careless and unsuited for my job because of my different cultural background." Her alternative thoughts in a later analysis included, "I have to accept that it is OK to talk with a foreign accent," "it is OK to be nervous when talking in front of a group of Danish people with quite a different cultural background," and "my cultural background does not mean that I am not a free woman." In accordance with these examples, almost all her problems with social anxiety were related to her different cultural background. After her initial high anxiety, she learned to appreciate the group, commented on the other group members' problems in a socially intelligent (and culturally appropriate) way, and she was moved by the positive feedback from "native Danish" people on her appearance and performance in the exposure exercises. She probably also profited somewhat from learning that Danish people constitute a rather heterogeneous group with different problems and attitudes, and that there in this group were very few stereotyped cultural prejudices.

In the following weekly group therapy she stated that the group experience had made it easier for her to assert herself on her job. In this period she was able to do exposure homework with some success on her phobic avoidance, e.g., being in the cellar for a longer period, travelling by buses, and bathing alone.

d. Response to therapy. Due to problems with language and cultural differences, Laila was only given four of the standardized scales (the BAI, BDI-II, SPS and SIAS); and she was not given the individualized, Evaluation of Social Phobia scales reported in Figure 2. According to the four standardized scales, there was symptomatic decline in anxiety and, especially, depression immediately after therapy (see Table 3I). There was, however, little change at followup (because she travelled to her native country in the summer, the follow-up was four months after the end of group therapy). At that time there were escalating conflicts with her husband at home and other problems in the family.

Laila was very grateful to her therapist and valued the therapy highly in and after therapy. Immediately after therapy she seemed to have profited from treatment with a reduction of depression and trauma related phobic avoidance. She evaluated the emotional ventilation in the 
A Novel Group Therapeutic Format in Cognitive Behavioral Treatment for Clients with Social

Phobia in a Training Setting: A Case Study of One Treatment Group with Nine Clients

E. Hougaard, S.S. Madsen, L.M. Hansen, M. Jensen, G.S. Katborg,

L. Morsaa, M. Pedersen, S.M. Pedersen, \& J. Piet

Pragmatic Case Studies in Psychotherapy, http://pcsp.libraries.rutgers.edu

Volume 4, Module 4, Article 1, pp. 1-52, 12-15-08 [copyright by authors]

individual therapy, "It helps me a lot to tell about the violent events I have experienced. It is relieving, and gives me more energy in my daily life."

There were, however, no clinically visible permanent changes in her condition at followup, when she again avoided trauma related phobic situations. We judged "no change" on the CGI at the time of follow-up. Serious family problems with escalating conflicts with her husband were, probably, an obstacle to durable therapeutic change. Besides, her main problem was not social phobia.

\section{Effect Sizes of the Whole Group}

We calculated pre-to-post-therapy (immediately after weekly group treatment) effect sizes for the 8 (out of 9) clients with accessible data after group-treatment (we had no posttreatment data from Peter due to his travelling abroad). We also calculated pre-to-follow-up (two months after group treatment or at the end of individual therapy) effect sizes for the 6 or 7 clients depending on the measure (Laila did not fill out all scales due to language problems) with accessible data at follow-up (there were no follow-up data on Mona and Cecilia). Effect sizes were calculated according to the formula for Cohen's $d$ : $\left(M_{\text {before }}-M_{a f t e r}\right) / S D$ (within $)_{\text {pooled }}$ (Cohen, 1988; Rosenthal, 1984), and the results are presented in Table 4.

As shown in Table 4, effect sizes were large (.83 to 1.27) and a bit higher at follow-up than immediately after group-treatment.. Four of the 7 clients with follow-up data (Niels, Ann, John, and Mary) received individual therapy in the follow-up period.

\section{Number of Clients Responding}

Table 5 presents the clients' outcomes on the SPS and SIAS according to different combinations of three criteria of change from pre-to-post-therapy, and from pre-to-follow-up (cf. section 1 on definitions of outcome).

As can be seen in Table 5, all clients except Laila (who did not have a clinical diagnosis of social phobia) had statistical significant change on at least one of the two social phobia scales after treatment as well as at follow-up. Thus, all social phobic clients improved to some degree on their self-reported disorder-specific symptoms.

Perhaps the most satisfactory definition of response is large or statistical and clinical significant change on at least one of the two scales, since their respective relevance might vary for different clients with social phobia (i.e., SPS is most relevant for specific social phobia, and SIAS is most relevant for generalized social phobia [Mattick \& Clarke, 1998]). According to this criterion, the number of clients responding is 6 out of $8(75 \%)$ after treatment, and 5 out of 7 $(71 \%)$ at follow-up. These figures are based on clients handing in scales at the respective data points. Calculation with post-treatment scores carried forward in case of missing follow-up data shows 7 out of 9 clients ( $78 \%$ ) responding according to this criterion at the latest point of assessment (i.e., all except Laila and Ann). 
A Novel Group Therapeutic Format in Cognitive Behavioral Treatment for Clients with Social

Phobia in a Training Setting: A Case Study of One Treatment Group with Nine Clients

E. Hougaard, S.S. Madsen, L.M. Hansen, M. Jensen, G.S. Katborg,

L. Morsaa, M. Pedersen, S.M. Pedersen, \& J. Piet

Pragmatic Case Studies in Psychotherapy, http://pcsp.libraries.rutgers.edu

Volume 4, Module 4, Article 1, pp. 1-52, 12-15-08 [copyright by authors]

As mentioned before, from the therapist's and supervisor's perspective, 6 out of the 9 clients $(67 \%)$ were judged to be responders on the CGI (i.e., "much" or "very much improved"). There were discrepancies for three clients with regard to their responder status based on the selfreport scales, SPS and SIAS, and therapist/supervisor CGI ratings at the latest point of observation. Specifically, Mona and Cecilia ranked higher on the self-report scales, and Ann ranked higher on the therapist/supervisor CGI rating.

\section{CONCLUDING EVALUATION OF THE TREATMENT PROGRAM}

\section{The Clinical Value of the Treatment Program}

\section{Overall Outcome of the Treatment Program}

From the therapist's and supervisor's point of view, 6 of the 9 clients $(67 \%)$ were judged to be responders on the CGI, while on the client self-report social phobia scales (SPS and SIAS), 7 of 9 clients (78\%) responded, with large or clinical and statistical change on at least one of the two scales (see Tables 2 and 5). As shown in Table 4, the pre-to-post-therapy effect sizes for the whole group were .95 and .92 for symptoms of social phobia on the SPS and SIAS, respectively, after group-treatment. And the pre-to-follow-up effect sizes were .98 and 1.17, respectively. These figures compare favorably with therapy outcome effect sizes based on selfreport measures of social phobia in the largest meta-analysis of CBT for social phobia to date by Federoff \& Taylor (2001), specifically, .84 for pre-to-post-therapy, and .95 for pre-to-follow-up.

The results thus support our clinical impression that the services provided by our clinical psychology students in the Aarhus Anxiety Clinic are valuable for social phobia clients from a therapeutic point of view. The study is in line with other studies supporting the idea that inexperienced therapists (who were in charge of most of the treatment) under supervision are capable of using evidence-based therapeutic methods in a satisfactory way (cf. Cukrowicz et al., 2005; Foa et al., 2005). In part, the positive results achieved by inexperienced student therapists might be explained by the fact that, relatively, they have few clients and a good deal of time for them, both for offering further sessions and for reflecting on their cases. One of the reasons for findings that experienced therapists don't always achieve better results than inexperienced therapists (e.g., Christensen \& Jacobson, 1994; Stein \& Lambert, 1995) might be the higher caseload among the former (Stein \& Lambert, 1995). At least one study found higher caseload of clients among therapists to predict lower outcomes (Vocisano et al., 2004).

\section{The Intensive Group-Program}

Clients were generally highly satisfied with the intensive group-week, and most of them achieved impressive symptomatic changes over the week (see Figures 2A to 2I). All clients, except Cecilia, emphasized this part of the treatment as very important for their treatment outcome. Within the intensive group-week all responding clients seemed to profit considerably from the behavioural experiments with video-feedback, which is in accordance with Clark and Wells' (1995) theoretical model of and treatment program for social phobia. 
A Novel Group Therapeutic Format in Cognitive Behavioral Treatment for Clients with Social

Phobia in a Training Setting: A Case Study of One Treatment Group with Nine Clients

E. Hougaard, S.S. Madsen, L.M. Hansen, M. Jensen, G.S. Katborg,

L. Morsaa, M. Pedersen, S.M. Pedersen, \& J. Piet

Pragmatic Case Studies in Psychotherapy, http://pcsp.libraries.rutgers.edu

Volume 4, Module 4, Article 1, pp. 1-52, 12-15-08 [copyright by authors]

Although the intensive group-week is highly anxiety provoking for most clients, we have until now (where we have just finished our fourth social phobia intensive week-program) had no drop-outs during the week (two clients dropped out before the intensive week in the first year of the clinic due to their work or study). In our experience, then, the intensive format is well accepted by social phobia clients, and it might even reduce drop-out compared to traditional weekly group therapy. This might be because there is little time between sessions for anxious worrying about the next meeting and the clients' public commitments by signing up for the whole week, which is known by relatives or friends, and, sometimes, by employers or school authorities.

We have also successfully used the intensive treatment format with panic- disordered clients. The close and massive being together over the week creates an elevated emotional spirit and a high degree of engagement in most clients within a supportive context, which might be geared to breaking down phobic evasiveness -- a "barrier breaking" experience as one of our clients, John, expressed it. The following 6 weekly group sessions aim at consolidating change and transferring the success experiences from the treatment group into clients' daily living, which is, probably, an important task since their acquired skills need to be integrated into their daily living.

Although there are few studies, it has been widely assumed that massed exposure will result in the largest immediate change, but that spaced exposure will achieve more durable effects (Barlow, 2002). As an empirical exploration of this issue, our own research team has compared an intensive, massed, 3-week 26-hour group CBT program for panic disorder (20 hours in the first week) with traditional weekly group CBT spread over 13 weeks in a randomized controlled trial. We found, however, no differences in outcomes between the two treatment conditions post-treatment or at follow-ups up to 18 months after treatment (Johansen et al., submitted). Social phobia clients, however, have a high degree of characterological involvement, and most of the clients in this program seemed to profit from the following group and individual therapy. Anyhow, almost all clients appreciate the offer of further therapy after the intensive group-week.

\section{Representativeness of Results}

The consecutive recruitment of clients in the study seemed to contribute to obtaining a rather representative sample of socially phobic clients at our clinic. Six out of the 9 clients -67 $\%$ - were judged responders on the CGI (i.e., "much" or "very much improved") compared to also $67 \%$ (6 out of 9) in our latest completed social phobia program, and $61 \%$ as judged by student therapists in an informal assessment of all 33 clients who finished treatment in the first year of the clinic. Thus, the outcomes in this study might be rather representative of those generally achieved among clients at the Anxiety Clinic at the Psychological Department. 
A Novel Group Therapeutic Format in Cognitive Behavioral Treatment for Clients with Social

Phobia in a Training Setting: A Case Study of One Treatment Group with Nine Clients

E. Hougaard, S.S. Madsen, L.M. Hansen, M. Jensen, G.S. Katborg,

L. Morsaa, M. Pedersen, S.M. Pedersen, \& J. Piet

Pragmatic Case Studies in Psychotherapy, http://pcsp.libraries.rutgers.edu

Volume 4, Module 4, Article 1, pp. 1-52, 12-15-08 [copyright by authors]

\section{Differences in Treatment Response}

\section{$\underline{\text { Individual Responses to Treatment }}$}

As mentioned in section 3C, social phobia clients highly diverge with regard to personality and treatment response. In this study there was also substantial individual variation in how the clients responded to the treatment program. The two clients with the best results according to the CGI, Niels and Vera, were very different. Niels was a highly disturbed young man with serious comorbid conditions, but he was also very motivated and dedicated to make use of the extensive treatment he was offered (e.g., 17 individual sessions after group treatment). Niels' motivation combined with the length of individual therapy seemed to have played an important role in his therapeutic change process. Niels might be considered an example of what many therapists would consider an "ideal client," with a high degree of motivation, relational capacity, and psychological insight combined with serious distress leaving much room for positive therapeutic change.

On the other hand, Vera, a middle aged woman, was not very disturbed, although clearly distressed and disabled by her specific social phobia. She received no extra individual therapy after the end of group therapy. Vera had never before had any treatment for her condition, and she rather quickly learned to use the new cognitive strategies in a supportive social context at home and at work. When she, at first with some hesitation, dared to make small changes at work, she was met with positive responses from her colleagues, thus starting a positive cycle of change. Vera represents a rather common type of specific socially phobic client with no other striking disturbances. Most people like Vera would not apply for treatment, and, if they do apply, they might risk that their general practitioner would deny them further referral since he or she considers them just to be shy people. People like Vera might, however, achieve very helpful changes with a small amount of problem-focused treatment.

John was another highly disturbed client who made impressive progress during treatment and had very large changes on the quantitative scales (see Table 3D). John also had rather extensive treatment ( 5 individual sessions before, and 9 after group treatment). His successful completion of the limited-period job offer, supported by his individual therapy, might also have played a role in his positive changes in the follow-up period.

The clients who changed least satisfactorily according to the CGI were Mona, Cecilia and Laila. Mona was very enthusiastic after the intensive group-week, with large changes on the Evaluation of Social Phobia scale (Appendix A), as well as on the two normed social phobia scales, SPS and SIAS, after the weekly group therapy (see Figure $2 \mathrm{G}$ and Table $3 \mathrm{G}$, respectively). She did, however, sometimes behave in an idiosyncratic way in therapy with apparently little profit from ordinary social phobia exposure tasks (cf. Mona's case history above). Her tendency to cognitively dichotomize and to be highly resentful in interpersonal relationships made her a rather difficult client, not well-suited to this problem-focused form of treatment administered by inexperienced student therapists. 
A Novel Group Therapeutic Format in Cognitive Behavioral Treatment for Clients with Social

Phobia in a Training Setting: A Case Study of One Treatment Group with Nine Clients

E. Hougaard, S.S. Madsen, L.M. Hansen, M. Jensen, G.S. Katborg,

L. Morsaa, M. Pedersen, S.M. Pedersen, \& J. Piet

Pragmatic Case Studies in Psychotherapy, http://pcsp.libraries.rutgers.edu

Volume 4, Module 4, Article 1, pp. 1-52, 12-15-08 [copyright by authors]

Cecilia did not score very high on any of the quantitative scales before therapy (seeTable $3 \mathrm{H})$. Probably her main problem was - as she herself realized - related to high ambitions in her school performance internalized from the relationship with her father in childhood and youth. She was not able to fulfill her ambitions, e.g. to get the high grades she would prefer, and thus it might have been valuable for her to relax her perfectionist demands on herself and become more accepting of her actual performance. Individual, schema-focused therapy might have helped her with that, but she had to leave therapy because of the timing of her baby's delivery.

Laila, the client with a foreign cultural background, had a sub-threshold diagnosis of PTSD as her main problem and no formal social phobia diagnosis (only social phobic traits). Thus, the treatment program was not tailor-made for her. Rather, her main problem seemed to be her serious conflicts with her husband due to his break with their daughter after her marriage disapproved by him. The conflicts grew over the follow-up period and there was nothing Laila could do to change her husband's attitude. She considered divorce, but divorce is a very serious step to take in her culture. Social problems experienced to be insoluble will, of course, limit benefits from any form of psychotherapy.

\section{$\underline{\text { Disordered Personality Traits }}$}

Widiger (1992) points out that generalized social phobia in many ways resembles a personality disorder, e.g., by starting early in life and influencing self-concept and relations to significant others. In a related vein, and as mentioned before, social phobia is highly comorbid with personality disorders. With these two points in mind, it is noteworthy that 6 of the 8 clients in the sample (Laila did not fill out this scale) scored above the threshold of 20 positive items on the SCID-II-Q, which according to McCullough et al. (2003) indicates a need of personality focused treatment. Consistent with Widiger's point of view, these 6 included all 4 of the clients in the study with a primary diagnosis of generalized social phobia. All 4 clients had additional individual therapy. The other two clients with above-threshold scores on the SCID-II-Q, Mona and Peter, both diagnosed with specific social phobia, were also judged to be in need of individual, personality-focused therapy. However, both dropped out of treatment, Peter for practical reasons and Mona because of personal conflicts (see their respective case vignettes). Thus, from a clinical point of view, McCullough et al.'s (2003) threshold seemed to be rather meaningful with this sample of social phobic clients.

\section{$\underline{\text { Length of Treatment }}$}

Some of our clients, most notably Niels and John (who achieved considerable change in the follow-up period [cf. Tables 3A and 3D]), apparently profited from rather extensive treatment with individual sessions after the end of the group program. According to the review by Orlinsky, Rönnestad and Willutzki (2004) treatment length is, generally, associated with better outcome, although a positive correlation is not always found in naturalistic studies, since duration of therapy is tailored to clients' needs (Stiles, Barkham, Connell, \& Mellor-Clark, 2008). We calculated a Pearson correlation for the association between number of sessions (apart from the intensive group-week) and residualized change scores (with pre-treatment level as a covariate) on SPS and SIAS (residualized change scores adjust for pre-treatment differences). 
A Novel Group Therapeutic Format in Cognitive Behavioral Treatment for Clients with Social

Phobia in a Training Setting: A Case Study of One Treatment Group with Nine Clients

E. Hougaard, S.S. Madsen, L.M. Hansen, M. Jensen, G.S. Katborg,

L. Morsaa, M. Pedersen, S.M. Pedersen, \& J. Piet

Pragmatic Case Studies in Psychotherapy, http://pcsp.libraries.rutgers.edu

Volume 4, Module 4, Article 1, pp. 1-52, 12-15-08 [copyright by authors]

The calculation was for the pre-to-follow-up scores, with post-treatment scores carried forward in case of missing follow-up data. Correlations were rather substantial but not statistically significant (for SPS: $r_{p}=.52, n=9, p=.15$; for SIAS: $r_{p}=.41, n=9, p=.27$ ). We also calculated a Spearman correlation for the association between number of sessions and CGI scores reversed (since lower numbers indicates greater change) with a comparable result $\left(r_{s}=.50, n=9, p=.17\right)$. While such calculations are suggestive, they are, however, of limited value, partly due to very small number of clients, and partly due to the fact that treatment was scheduled according to each client's clinically perceived needs.

\section{The Educational Aspects of the Program}

As mentioned in section 1 on design, the educational benefits for the students in the program were not formally studied. The following comments are, primarily, based on rational considerations and informal discussions among the students and the supervisor in this social phobia program (the students are co-authors of the article).

Anxiety disordered clients are, mostly, rather easy to handle by beginning therapists, and it is well established that such clients respond well to CBT. So, both the clientele and the treatment method might be well suited for training purposes in a university setting. As can be seen in the case vignettes in section 4-7, no clients in this group seemed to be harmed by the therapy; and until now, in the fourth year of the program, there have been no serious untoward events among the clients in the clinic. Students generally have appreciated to be able to follow a manual when they start doing therapy, although most of them rather quickly learned also to trust their intuition and to use the techniques in a flexible way.

Almost all students have evaluated the practical aspects of the program with the highest degree of satisfaction in the course evaluations questionnaire -- which should come as no surprise, since it is at present the only psychotherapeutic training program at the institute. Based on informal impressions, students have been especially enthusiastic about the intensive groupweek with its mix of therapist demonstrations and their own functioning as therapists. For the students this arrangement is very informative, since they get to see experienced therapists working with the students' own clients, whom they know from earlier individual therapy sessions; and it is highly satisfactory for them to "learn by doing" in gradually taking over responsibility for treatment. The supervisor's demonstration of therapeutic techniques and attitudes has been considered an important part of the training of new psychotherapists since the pioneering works by Carl Rogers (1957) and Truax and Carkhuff (1967).

The close co-operation among students in the program provided an opportunity to observe and learn from other students' doing in vivo therapy as well as from mutual feedback in their informal peer-supervision. The group format also made it possible for students to follow many different clients in therapy. The fast and impressive changes the students witnessed among the clients in the intensive group-week convinced most, even among the few sceptics, of the advantages of CBT for anxiety-disordered clients. 
A Novel Group Therapeutic Format in Cognitive Behavioral Treatment for Clients with Social

Phobia in a Training Setting: A Case Study of One Treatment Group with Nine Clients

E. Hougaard, S.S. Madsen, L.M. Hansen, M. Jensen, G.S. Katborg,

L. Morsaa, M. Pedersen, S.M. Pedersen, \& J. Piet

Pragmatic Case Studies in Psychotherapy, http://pcsp.libraries.rutgers.edu

Volume 4, Module 4, Article 1, pp. 1-52, 12-15-08 [copyright by authors]

Most students found the demand for a systematic case study of at least one client as part of their examination highly interesting, but at the same time challenging and time-consuming. The case study sharpens the students' reflections on details of their cases, and it surely disproves the common assumption among them that psychotherapists intuitively know all there is to know about their clients.

The supervisors and teachers were also highly satisfied with the educational program. There is an advantage in supervising work with clients one knows at first hand from one's own therapeutic work. The presence of the clients' individual student therapists in the intensive group-week facilitated shared understanding of the clients as well as client attendance at the meetings. The program provides many of the ingredients, generally assumed to be important in a training program for beginning psychotherapists, with a rather small amount of training resources - a consideration that is at present highly relevant in the Danish university system.

\section{Qualitative and Quantitative Evaluation of Change}

Quantification of measures is an important means to balance and complement subjectivity in single-case research (e.g., Hayes, Barlow and Nelson-Gray, 1999). On the other hand, "thick description" of client functioning before and after therapy as a qualitative assessment of outcomes has been suggested as an important complement to psychometric scales with "arbitrary metrics" (cf. Kazdin, 2006). This study attempts to use conventions (see Appendix B) from group studies aimed at defining clinically important categories of change on quantitative scales for individual clients (e.g., Bauer et al., 2004; Ogles, Lambert \& Masters, 1996). From a clinical point of view the conventions seemed to be meaningful, although the cutoff points are based on fragile information due to unsatisfactory standardizations of most scales and almost no Danish norms (the one exception is SCL-90). Clinically established cut-off points based on in-depth, qualitative studies might be a solution to the problems related to clinically significant change (cf. Bauer et al, 2004).

In this study, there were some correspondence between responder status based on the two primary quantitative self-report measures of change (the SPS and SIAS) and on therapist's/supervisor's judgements on the CGI. On the other hand, there were also differences, as exemplified by three cases, Cecilia, Ann and Mona. For Cecilia, who was judged responder on the self-report measures, but not on the CGI, the discrepancy might be rather trivial, since her responder status on self-report measures was based on her SPS score being moved from the clinical to the normal range, and her pre-treatment score on SPS of 25.0 was only 0.1 above the cut-off line between normal and pathological functioning on the scale (see Table $3 \mathrm{H}$ and $3 \mathrm{~K}$ ).

In the case of Ann, who was judged a responder on the CGI but not on the self-report scales, we were impressed in the therapist/supervisor rating by the changes in her life-style after therapy that she told us about as well as by her very enthusiastic statements about how she would now respond to her problems (see case vignette of Ann). She also showed large changes on the general symptomatic scales of anxiety and depression, the BAI and the BDI-II, although not on the disorder-specific social phobia scales. In the case of Mona, with responder status only on self-report scales, we judged her main problem to be her personality functioning and thus were 
A Novel Group Therapeutic Format in Cognitive Behavioral Treatment for Clients with Social

Phobia in a Training Setting: A Case Study of One Treatment Group with Nine Clients

E. Hougaard, S.S. Madsen, L.M. Hansen, M. Jensen, G.S. Katborg,

L. Morsaa, M. Pedersen, S.M. Pedersen, \& J. Piet

Pragmatic Case Studies in Psychotherapy, http://pcsp.libraries.rutgers.edu

Volume 4, Module 4, Article 1, pp. 1-52, 12-15-08 [copyright by authors]

less impressed by her changes on specific social phobic symptoms. Although we have most confidence in our CGI judgments, the possibility exists that we overestimated the outcome of Ann and underestimated that of Mona. No gold standard exists of how best to evaluate therapeutic outcome.

In our CGI judgments of outcome, we make use of some of the same dimensions as in the quantitative evaluation of clinical significance, for example, the magnitude of change and whether end-state functioning is within what we consider the range of normal functioning. However, the qualitative information employed in our CGI ratings differs from scores on the social-phobia-specific self-report measures of the SPS and SIAS, and we consider other aspects than disorder-specific symptoms in our evaluations - e.g., other symptoms, personality and concrete behavioral changes, in the context of all of the objectives of treatment. This flexible use of many dimensions might, of course, be both a strength and a weakness. Further studies on the relationship between ratings based on qualitatively rich material like the CGI and standardized self-report evaluations of change on measures like the SPS and SIAS should be theoretically informative.

\section{Case-Based and Group-Based Analyses}

Like qualitative and quantitative analyses, case-based and group-based analyses might balance and complement each other. The group-based, quantitative analyses facilitate comparisons with other group studies, and thus the general evaluation of the clinical program based on effectiveness. The individual case vignettes, on the other hand, offer more detailed information on the different clients and their treatment with some plausible explanations of why they did, or did not, respond. The relevance of the analyses of differential responding among the clients might be argued with reference to case-based analysis, i.e. every case is a possible source of knowledge.

\section{Limitations}

This study has several limitations. The individual case studies could have been studied in more details, e.g. with systematic use of the video-recordings. There were problems with obtaining completed questionnaires from clients, especially the individualized, "Evaluation of Social Phobia" scales (see Appendix A). More data points would have strengthened reliability for measuring change as well as the possibility of evaluating client progress over the course of a therapy with different treatment modalities. Moreover, the design was complex with a high degree of variability in the treatment for different clients, which, however, also might be considered a strength, since it mirrors ordinary conditions in the clinic.

\section{Conclusions}

The integration of the pragmatic case study strategy (Fishman, 2000; 2005) within an educational setting aimed at teaching students psychotherapeutic skills has had value from a variety of perspectives. This case-based evaluation provides support for the clinical value and feasibility of the new treatment program for social phobia clients at the Anxiety Clinic of the 
A Novel Group Therapeutic Format in Cognitive Behavioral Treatment for Clients with Social

Phobia in a Training Setting: A Case Study of One Treatment Group with Nine Clients

E. Hougaard, S.S. Madsen, L.M. Hansen, M. Jensen, G.S. Katborg,

L. Morsaa, M. Pedersen, S.M. Pedersen, \& J. Piet

Pragmatic Case Studies in Psychotherapy, http://pcsp.libraries.rutgers.edu

Volume 4, Module 4, Article 1, pp. 1-52, 12-15-08 [copyright by authors]

Department of Psychology of the University of Aarhus. Most clients achieved fast symptomatic declines in the program. Moreover, the students were highly satisfied with the program and seemed to learn therapeutic skills and attitudes in a rather short time. The demand for a systematic case study might help to instill a scientist-practitioner attitude in the students. As mentioned before, students also have more time than practicing therapists for the extensive work of gathering and systematizing detailed information on individual clients. Thus, an educational clinic may be especially suited for efforts to build up a comprehensive database of systematic case studies (see Fishman, 2005).

\section{REFERENCES}

Alonso, J., Angermeyer, M.C., Bernert, S., Bruffaerts, R., Brugha, R.S, Bryson, H. et al. (2004). Prevalence of mental disorders in Europpe: Results from the European Study of the Epidemiology of Mental Disorders (ESEMeD) project. Acta Psychiatrica Scandinavia., 109 (Suppl. 420), 21-27.

American Psychiatric Association (APA) (1994). Diagnostic and statistical manual of mental disorders, $4^{\text {th }}$ edition (DSM-IV). Washington, DC: American Psychiatric Association.Barlow, D.H. (2002). Anxiety and its disorders (2 ${ }^{\text {nd }}$ ed.). New York: Guilford.

Barlow, D.H., Hayes, S.C. \& Nelson-Gray, R.O. (1999). The scientist practitioner: Research and accountability in clinical and educational settings. New York: Pergamon Press.

Bauer, S., Lambert, M.J. \& Nielsen, S.L. (2004). Clinical significance methods: A comparison of statistical techniques. Journal of Personality Assessment, 82, 60-70.

Beck, A.T., Freeman, A. \& Davis, D.D. (2004). Cognitive therapy of personality disorders. New York: Guilford.

Beck, A.T. \& Steer, R.A. (1993). Beck Anxiety Inventory manual. San Antonio, TX: Psychological Corporation.

Beck, A.T., Steere, R.A. \& Brown, G.K. (1996). Manual for the revised Beck Depression Inventory. San Antonio. TX: The Psychological Corporation.

Beck, J.S. (1995). Cognitive therapy: Basics and beyond. New York: Guilford.

Brown, T.A., Di Nardo, P.A. \& Barlow, D.A. (1994). Anxiety Disorder Interview Schedule for DSM-IV: Adult version. New York: Graywind Publication.

Christensen, A. \& Jacobson, N.S. (1994). Who (or what) can do psychotherapy: The status and challenge of nonprofessional therapists. Psychological Science, 5, 8-14.

Clark, D.M. (1997). Panic disorder and social phobia. I D.M. Clark \& C.G. Fairburn (eds.), Science and practice of cognitive behavior therapy (pp. 122-153). New York: Oxford University Press.

Clark,D.M., Ehlers, A., Hackmann, A., McManus, R. Fennell, M., Grey, N., Waddington, L. \& Wild, J. (2006). Cognitive therapy versus exposure and applied relaxation in social phobia: A randomized trial. Journal of Consulting and Clinical Psychology, 74, 568-578.

Clark, D.M. \& Wells, A. (1995). A cognitive model of social phobia. In: R.G. Heimberg, M.R. Liebowitz, D.A. Hope \& F.R. Scheier (eds.), Social phobia: Diagnosis, assessment, and treatment. New York: Guilford.

Cohen, J. (1988). Statistical power analysis for the behavioral sciences ( $2^{\text {nd }}$ ed.). Hillsdale, NJ: Erlbaum. 
A Novel Group Therapeutic Format in Cognitive Behavioral Treatment for Clients with Social

Phobia in a Training Setting: A Case Study of One Treatment Group with Nine Clients

E. Hougaard, S.S. Madsen, L.M. Hansen, M. Jensen, G.S. Katborg,

L. Morsaa, M. Pedersen, S.M. Pedersen, \& J. Piet

Pragmatic Case Studies in Psychotherapy, http://pcsp.libraries.rutgers.edu

Volume 4, Module 4, Article 1, pp. 1-52, 12-15-08 [copyright by authors]

Cukrowicz, K.C., White, B.A., Reitzel, L.R, Burns, A.V., Driscoll. K.A., Kemper, T.S. \& Joiner, T.E. (2005). Improved treatment outcome associated with the shift to empirically supported treatments in a graduate training clinic. Professional Psychology: Research and Practice, 36, 330-337.

Davidson, J.R.T., Foa, E.B., Huppert, J.D., Keefe, F.J., Franklin, M.E., Compton, J.S., Zhao, N. et al. (2004). Fluoxetine, comprehensive cognitive behavioral therapy, and placebo in generalized social phobia. Archives of General Psychiatry, 61, 1005-1013.

Derogatis, L.R. (1977). SCL-90-R: Administration, scoring, and procedures manual. Baltimore: Clinical Psychometric Research.

Dias, W.P.S. (2007). Philosophical grounding and computational formalization for practice based engineering knowledge. Knowledge-Based System, 20, 382-387.

Dyck, I. R., Phillips, K. A., Warshaw, M. G., Dolan, R. T., Shea, M. T., Stout, R. L., Massion, A. O., Zlotnick, C., \& Keller, M. B. (2001). Patterns of personality pathology in clients with generalized anxiety disorder, panic disorder with and without agoraphobia, and social phobia. Journal of Personality Disorders, 15, 60-71.

Edwards, D.J.A., Dattillio, F.M. \& Bromley, D.B. (2004). Developing evidence-based practice: The role of case-based research. Professional Psychology: Research and Practice, 35, 589-597.

Edwards, D. J.A., Kannan, S. (2006). Identifying and targeting idiosyncratic cognitive processes in group therapy for social phobia: The Case of Vumile. Pragmatic Case Studies in Psychotherapy [Online], Vol. 2(1), Article 1, 1-30. Available: http://hdl.rutgers.edu/1782.1/pcsp journal.

Foa, E.B., Hembree, E.A., Cahill, S.P., Rauch, S.A.M., Riggs, D.S., Feeny, N.C. \& Yadin, E. (2005). Randomized trial of prolonged exposure for posttraumatic stress disorder with and without cognitive restructuring: Outcome at academic and community clinics. Journal of Consulting and Clinical Psychology, 73, 953-964.

Fedoroff, I.C. \& Taylor, S. (2001). Psychological and pharmacological treatments of social phobia: A meta-analysis. Journal of Clinical Psychopharmacology, 21, 311-324.

First, M.B., Gibbon, M., Spitzer, R.L., Williams, J.F.W. \& Benjamin, L.S. (1997). SCID-II Personality Questionaire. Washington, DC: American Psychiatric Press.

Fishman, D.B. (2000). Transcending the efficacy versus effectiveness research debate: Proposal for a new, electronic "Journal of Pragmatic Case Studies." Prevention \& Treatment, 3, Article 8. Available on the World Wide Web: http://journals.apa.org/prevention/volume3/pre0030008a.html.

Fishman, D. B. (2005). Editor's introduction to PCSP - From single case to database: A new method for enhancing psychotherapy practice. Pragmatic Case Studies in Psychotherapy [Online], Vol. 1(1), Article 2, 1-50. Available: http://hdl.rutgers.edu/1782.1/pcsp journal.

Furmark, T. (2002). Social phobia: overview of community surveys. Acta Psychiatrica Scandinavica, 105, 84-93.Guy, W. (1976). ECDEU assessment manual for psychopharmaca, revised. Washington, DC: US Government Printing Office. DHEW publication ADM 76-338.

Gillis, M.M., Haaga, D.A.F. \& Ford, G.T. (1995). Normative values for the Beck Anxiety Inventory, Fear Questionnaire, Penn State Worry Questionnaire, and Social Phobia and Anxiety Inventory. Psychological Assessment, 7, 450-455. 
A Novel Group Therapeutic Format in Cognitive Behavioral Treatment for Clients with Social

Phobia in a Training Setting: A Case Study of One Treatment Group with Nine Clients

E. Hougaard, S.S. Madsen, L.M. Hansen, M. Jensen, G.S. Katborg,

L. Morsaa, M. Pedersen, S.M. Pedersen, \& J. Piet

Pragmatic Case Studies in Psychotherapy, http://pcsp.libraries.rutgers.edu

Volume 4, Module 4, Article 1, pp. 1-52, 12-15-08 [copyright by authors]

Heimberg, R.G. \& Becker, R.E. (2001). Cognitive-behavioral group therapy for social phobia: Basic Mechanisms and Clinical Strategies. New York: Guilford Press.

Heimberg, R.G., Liebowitz, M.R., Hope, D.A., Schneier, F.R., Holt, C.S., Craig, S., Welkowitz, L.A. et al. (1998). Cognitive-behavioral group therapy versus phenelzine in social phobia: 12-week outcome. Archives of General Psychiatry, 55, 1133-1141.

Horowitz, L.M., Alden, L.E., Wiggins, J.S. \& Pincus, A.L. (2000): IIP: Inventory of Interpersonal Problems - Manual. San Antonio, TX: The Psychological Corporation.

Hougaard, E. (2006). Kognitiv behandling af panikangst og socialfobi: En vejledning for klienter og behandlere (Cognitive behavioral treatment for panic disorder and social phobia: A guideline for clients and therapists). København: Dansk Psykologisk Forlag.

Jacobson, N.S. \& Truax, P. (1991). Clinical significance: A statistical approach to defining meaningful change in psychotherapy research. Journal of Consulting and Clinical psychology, 59, 12-19.

Johansen, M.K., Spindler, H., Arendt, M., Hougaard, E. \& Rosenberg, N.K. (submitted) ). A new, 3-week massed group cognitive-behavioural treatment program for panic disorder: A comparative study.

Kazdin, A.E. (2006). Arbitrary metrics: Implications for identifying evidence-based treatments. American Psychologist, 61, 2006, 42-49.

Keller, M.B. (2003). The lifelong course of social anxiety disorder: A clinical perspective. Acta Psychiatrica Scandinavica, 108 (suppl. 417), 85-94.Kolodner, J.L. (1997). Educational implications of analogy: A view from case-based reasoning. American Psychologist, 52, 57-62.

Liebowitz, M.R., Heimberg, R.G., Schneier, F.R., Hope, D.A., Davies, S., Holt, C.S., Goetz, D. et al. (1999). Cognitive-behavioral group therapy versus phenelzine in social phobia: Long-term outcome. Depression and Anxiety, 10, 89-98.

Mattick, R.P. \& Clarke, J.C. (1998). Development and validation of measures of social phobia, scrutiny fear and social interaction anxiety. Behavior Research and Therapy, 36, 455470.

McCullough, L., Kuhn, N., Andrews, S., Kaplan, A., Wolf, J. \& Hurley, C.L. (2003). Treating affect phobia: A manual for short term dynamic psychotherapy. New York: Guilford Press.

Mörtberg, E, Clark, D.M., Sundin, Ö., Wisted, A. \& Åberg, A. (2006). Intensive group cognitive treatment and individual cognitive therapy vs. treatment as usual in social phobia: A randomized controlled study. Acta Psychiatrica Scandinavica, 115, 142-154.

Mörtberg, E., Karlsson, A., Fyring, C. \& Sundin, Ö. (2006). Intensive cognitive-behavioral group treatment (CBGT) of social phobia: A randomized controlled study. Anxiety Disorders, 20, 646-660.

Ogles, B.M., Lambert, J.J. \& Masters, K.S. (1996). Assessing outcome in clinical practice. Boston: Allyn \& Bacon.

Olsen, L.R., Mortensen, E.L. \& Bech, P. (2004). The SCL-90 and SCL-90R versions validated by item response models in a Danish community sample. Acta Psychiatrica Scandinavica, 110, 225-229. 
A Novel Group Therapeutic Format in Cognitive Behavioral Treatment for Clients with Social

Phobia in a Training Setting: A Case Study of One Treatment Group with Nine Clients

E. Hougaard, S.S. Madsen, L.M. Hansen, M. Jensen, G.S. Katborg,

L. Morsaa, M. Pedersen, S.M. Pedersen, \& J. Piet

Pragmatic Case Studies in Psychotherapy, http://pcsp.libraries.rutgers.edu

Volume 4, Module 4, Article 1, pp. 1-52, 12-15-08 [copyright by authors]

Orlinsky, D.E., Rönnestad, M.H. \& Willutzki, U. (2004). Fifty years of psychotherapy processoutcome research: Continuity and change. In: M.J. Lambert (ed.), Bergin and Garfield's handbook of psychotherapy and behavior change ( $5^{\text {th }}$ ed.). New York: Wiley.

Prentzas, J. \& Hatzilygeroudis, I. (2007). Categorizing approaches combining rule-based and case-based reasoning. Expert Systems, 24, 97-121,

Rapee, R.M. \& Spence, S.H. (2004). The etiology of social phobia: Empirical evidence and initial model. Clinical Psychology Review, 24, 737-767.

Rodebaugh, T.L., Holaway, R.M.\& Heimberg, R.G. (2004). The treatment of social anxiety disorder. Clinical Psychology Review, 24, 883-908.Rosenthal, R. (1984). Meta-analytic procedures for social research. Beverly Hills: Sage.Rosenthal, R. (1984). Meta-analytic procedures for social research. Beverly Hills: Sage.Rogers, C.R. (1957). Training individuals to engage in the therapeutic process. I: C.R. Strother (ed.), Psychology and mental health (pp. 76-92). Washington, DC: American Psychological Association.

Sanderson, W. C., Wetzler, S., Beck, A. T., \& Betz, F. (1994). Prevalence of personality disorders among patients with anxiety disorders. Psychiatry Research, 51, 167174.Schön, D.A. (1983). The reflective practioner: How professionals think in action. New York: Basic Books.

Stangier, U., Heidenreich, T., Peitz, M., Lauterbach, W. \& Clark, D.M. (2003). Cognitive therapy for social phobia: Individual versus group treatment. Behavior Research and Therapy, 41, 991-107.

Stein, D.M. \& Lambert, M.J. (1995). Graduate training in psychotherapy: Are therapy outcomes enhanced? Journal of Consulting and Clinical Psychology, 63, 182-196.

Stiles, W.B., Barkham, M., Connell, J. \& Mellor-Clark, J. (2008). Responsive regulation of treatment duration in routine practice in United Kingdom primary care settings: Replication in a larger sample. Journal of Consulting and Clinical Psychology, 76, 298-302.

Strupp, H.H., Horowitz, L.M. \& Lambert, M.J. (Eds.). Measurng patient change in mood, anxiety and personality disorders: toward a core battery. Washington: American Psychological Association.

Taylor, S. (1996). Meta-analysis of cognitive-behavioral treatments for social phobia. Journal of Behavior Therapy and Experimental Psychiatry, 27, 1-9.Truax, C.G. \& Carkhuff, R.R. (1967). Toward effective counseling and psychotherapy: Training and practice. Chicago: Aldine.

Vocisano, C., Klein, D.N., Arnow, B., Rivera, C., Blalock, J.A., Rothbau, B., Vivian, D. et al. (2004). Therapist variables that predict symptom change in psychotherapy with chronically depressed outpatients. Psychotherapy: Theory, Research, Practice, Training, 41, 255-265.

Wang, W.M., Cheung, C.F., Lee, W.B. \& Kwok, S.K. (2007). Knowledge-based treatment planning for adolescent early intervention of mental healthcare: A hybrid case-based reasoning approach. Expert Systems, 24, 232-251.

Widiger, T.A. (1992). Generalized social phobia versus avoidant personality disorder: A commentary on three studies. Journal of Abnormal Psychology, 101, 340-343.

Yin, R.K. (1991). Case study research: Design and methods ( $8^{\text {th }}$ printing). London: Sage.

Young, J.E., Klosko, J.S. \& Weishaar, M.E. (2003). Schema therapy: A practioner's guide.New York, NY: Guilford. 
Phobia in a Training Setting: A Case Study of One Treatment Group with Nine Clients

E. Hougaard, S.S. Madsen, L.M. Hansen, M. Jensen, G.S. Katborg,

L. Morsaa, M. Pedersen, S.M. Pedersen, \& J. Piet

Pragmatic Case Studies in Psychotherapy, http://pcsp.libraries.rutgers.edu

Volume 4, Module 4, Article 1, pp. 1-52, 12-15-08 [copyright by authors]

\section{Table 1. Schedule of the Group Treatment Program at The Anxiety Clinic}

\begin{tabular}{|c|c|}
\hline Part of the Treatment Program & Primary Content of Treatment \\
\hline $\begin{array}{l}\text { Individual treatment with student } \\
\text { therapist prior to the intensive week } \\
\text { program } \\
2-4 \text { sessions }\end{array}$ & $\begin{array}{l}\text { Anamnestic history } \\
\text { Problem list and objectives of treatment } \\
\text { Case-formulation following the format of J. Beck (1995) }\end{array}$ \\
\hline $\begin{array}{l}\text { Intensive group treatment (five } \\
\text { consecutive days 9:00am to 2:00pm) } \\
\text { Day 1: Anxiety model and self-focused } \\
\text { attention }\end{array}$ & $\begin{array}{l}\text { Psychoeducation (anxiety, diagnoses, cognitive-behavioral therapy) } \\
\text { Clark \& Wells' (1995) model for social phobia filled out for all } \\
\text { clients } \\
\text { Exercises of focusing in- and outwards in pairs of clients }\end{array}$ \\
\hline $\begin{array}{l}\text { Day 2: Cognitive restructuring and } \\
\text { behavioral experiment }\end{array}$ & $\begin{array}{l}\text { Cognitive restructuring of negative thoughts in a situation with social } \\
\text { anxiety } \\
\text { Behavioral experiments with a small exposure exercise, e.g., reading } \\
\text { or telling something in front of a small group ( } 4 \text { or } 5 \text { clients and } 4 \\
\text { student-therapists) }\end{array}$ \\
\hline $\begin{array}{l}\text { Day 3: Exposure, safety behaviors, and } \\
\text { paradoxical strategies }\end{array}$ & $\begin{array}{l}\text { Psychoeducation concerning exposure and safety behaviors. } \\
\text { Behavioral experiments in the large group ( } 9 \text { clients, } 8 \text { student- } \\
\text { therapists, and } 2 \text { psychologists) with video-feedback }\end{array}$ \\
\hline Day 4: Exposure, continued & $\begin{array}{l}\text { Behavioral experiments in the large group ( } 9 \text { clients, } 8 \text { student- } \\
\text { therapists, psychologists may not be present) with video-feedback }\end{array}$ \\
\hline & $\begin{array}{l}\text { Relationship between self-concept, dysfunctional attitudes and } \\
\text { negative automatic thoughts }\end{array}$ \\
\hline $\begin{array}{l}\text { Day 5: Dysfunctional attitudes or rules of } \\
\text { life, self-concept }\end{array}$ & $\begin{array}{l}\text { Telling of life events that might have contributed to problems in a } \\
\text { small group ( } 4 \text { or } 5 \text { clients, } 4 \text { student-therapists) }\end{array}$ \\
\hline $\begin{array}{l}\text { Extensive group treatment in small } \\
\text { groups with student-therapists ( } 4 \text { or } 5 \\
\text { clients, } 4 \text { students) ( } 2 \text { hours a week for } 6 \\
\text { weeks) }\end{array}$ & \\
\hline $\begin{array}{l}\text { Session 1: Review of progress, exposure } \\
\text { plan }\end{array}$ & $\begin{array}{l}\text { Review change for all clients } \\
\text { Plan exposure steps to achieve treatment objective }\end{array}$ \\
\hline Session 2-5: Exposure in daily life & $\begin{array}{l}\text { Plan and review exposure homework, cognitive restructuring when } \\
\text { relevant }\end{array}$ \\
\hline Session 6: Status, end of therapy & $\begin{array}{l}\text { Review change for all clients } \\
\text { Discuss meaning of therapy ending } \\
\text { Review clients' use of treatment methods on their own }\end{array}$ \\
\hline
\end{tabular}


A Novel Group Therapeutic Format in Cognitive Behavioral Treatment for Clients with Social Phobia in a Training Setting: A Case Study of One Treatment Group with Nine Clients

E. Hougaard, S.S. Madsen, L.M. Hansen, M. Jensen, G.S. Katborg,

L. Morsaa, M. Pedersen, S.M. Pedersen, \& J. Piet

Pragmatic Case Studies in Psychotherapy, http://pcsp.libraries.rutgers.edu

Volume 4, Module 4, Article 1, pp. 1-52, 12-15-08 [copyright by authors]

Table 2. Summary of Client Characteristics

\begin{tabular}{|c|c|c|c|c|c|c|c|c|c|c|}
\hline $\begin{array}{l}\text { Clinical } \\
\text { Global } \\
\text { Index } \\
\text { ("CGI") }\end{array}$ & Client & Age & Occupation & $\begin{array}{l}\text { Civil } \\
\text { status }\end{array}$ & $\begin{array}{l}\text { Primary } \\
\text { diagnosis }\end{array}$ & $\begin{array}{l}\text { Comorbid } \\
\text { Diagnoses }\end{array}$ & $\begin{array}{l}\text { Number of } \\
\text { Positive } \\
\text { items in } \\
\text { SCID-II-Q }\end{array}$ & $\begin{array}{l}\text { Duration } \\
\text { of main, } \\
\text { presenting } \\
\text { problem }\end{array}$ & $\begin{array}{l}\text { Simultaneous medical } \\
\text { treatment in non-bold. } \\
\text { Prior treatments } \\
\text { in bold. }\end{array}$ & $\begin{array}{l}\text { Treatment } \\
\text { sessions } \\
\text { received }^{b}\end{array}$ \\
\hline $\begin{array}{l}\text { 1-Very } \\
\text { much } \\
\text { improved }\end{array}$ & 1. Niels & 26 & Student & Single & $\begin{array}{l}\text { Social phobia } \\
\text { (generalized) }\end{array}$ & $\begin{array}{l}\text { Recurrent major } \\
\text { depression } \\
\text { Panic disorder }\end{array}$ & 35 & Lifelong & $\begin{array}{l}\text { SSRI's 2002-06 } \\
\text { Prior CBT (6 sessions) } \\
\text { Escitalopram ( } 20 \mathrm{mg}) \\
2006-2007 \\
\end{array}$ & $\begin{array}{l}\mathrm{I}-\mathrm{B}=2 \\
\mathrm{GW}=5 \\
\mathrm{G}-\mathrm{A}=4 \\
\mathrm{I}-\mathrm{A}=17\end{array}$ \\
\hline $\begin{array}{l}\text { 1-Very } \\
\text { much } \\
\text { improved }\end{array}$ & 2. Vera & 45 & $\begin{array}{l}\text { Kindergarten } \\
\text { teacher }\end{array}$ & Married & $\begin{array}{l}\text { Social phobia } \\
\text { (specific) }\end{array}$ & & 6 & 10 years & $\begin{array}{l}\text { Prior benzodiazepines } \\
\text { and beta-blockers } \\
\text { from the GP }\end{array}$ & $\begin{array}{l}\mathrm{I}-\mathrm{B}=4 \\
\mathrm{GW}=5 \\
\mathrm{G}-\mathrm{A}=4 \\
\mathrm{I}-\mathrm{A}=0\end{array}$ \\
\hline $\begin{array}{l}\text { 2-Much } \\
\text { improved }\end{array}$ & 3. Ann & 28 & Shop worker & Single & $\begin{array}{l}\text { Social phobia } \\
\text { (generalized) }\end{array}$ & $\begin{array}{l}\text { Prior major } \\
\text { depressive } \\
\text { episode }\end{array}$ & 24 & 12 years & $\begin{array}{l}\text { SSRI's } 2002 \\
\text { Psychotherapy (10 } \\
\text { sessions) } 1997 \\
\text { Group course of CBT } \\
2003\end{array}$ & $\begin{array}{l}\mathrm{I}-\mathrm{B}=3 \\
\mathrm{GW}=5 \\
\mathrm{G}-\mathrm{A}=1 \\
\mathrm{I}-\mathrm{A}=7\end{array}$ \\
\hline $\begin{array}{l}\text { 2-Much } \\
\text { improved }\end{array}$ & 4. John & 23 & Unemployed & $\begin{array}{l}\text { Living with } \\
\text { girlfriend }\end{array}$ & $\begin{array}{l}\text { Social phobia } \\
\text { (generalized) }\end{array}$ & $\begin{array}{l}\text { Prior major } \\
\text { depressive } \\
\text { episode }\end{array}$ & 29 & 6 years & $\begin{array}{l}\text { Paroxetine }(40 \mathrm{mg} \text { ) } \\
\text { 2004- }\end{array}$ & $\begin{array}{l}I-B=5 \\
G W=5 \\
G-A=3 \\
I-A=9\end{array}$ \\
\hline $\begin{array}{l}\text { 2-Much } \\
\text { improved }\end{array}$ & 5. Mary & 24 & Student & $\begin{array}{l}\text { Living with } \\
\text { boyfriend }\end{array}$ & $\begin{array}{l}\text { Social phobia } \\
\text { (generalized) }\end{array}$ & $\begin{array}{l}\text { Major } \\
\text { depression } \\
\text { Dysthymia } \\
\text { Avoidant } \\
\text { personality } \\
\text { disorder? }\end{array}$ & 36 & Lifelong & & $\begin{array}{l}\mathrm{I}-\mathrm{B}=4 \\
\mathrm{GW}=5 \\
\mathrm{G}-\mathrm{A}=2 \\
\mathrm{I}-\mathrm{A}=6\end{array}$ \\
\hline
\end{tabular}

a See note at end of table.

${ }^{\mathrm{b}}$ See Note at end of table. 
A Novel Group Therapeutic Format in Cognitive Behavioral Treatment for Clients with Social

Phobia in a Training Setting: A Case Study of One Treatment Group with Nine Clients

E. Hougaard, S.S. Madsen, L.M. Hansen, M. Jensen, G.S. Katborg,

L. Morsaa, M. Pedersen, S.M. Pedersen, \& J. Piet

Pragmatic Case Studies in Psychotherapy, http://pcsp.libraries.rutgers.edu

Volume 4, Module 4, Article 1, pp. 1-52, 12-15-08 [copyright by authors]

Table 2 (continued)

\begin{tabular}{|c|c|c|c|c|c|c|c|c|c|c|}
\hline $\begin{array}{l}\text { 2-Much } \\
\text { improved }\end{array}$ & 6. Peter & 28 & Student & Married & $\begin{array}{l}\text { Social phobia } \\
\text { (specific) }\end{array}$ & & 22 & 16 years & & $\begin{array}{l}\mathrm{I}-\mathrm{B}=4 \\
\mathrm{GW}=5 \\
\mathrm{G}-\mathrm{A}=2 \\
\mathrm{I}-\mathrm{A}=0\end{array}$ \\
\hline $\begin{array}{l}\text { Clinical } \\
\text { Global } \\
\text { Index } \\
\text { ("CGI") }\end{array}$ & Client & Age & Occupation & $\begin{array}{l}\text { Civil } \\
\text { status }\end{array}$ & $\begin{array}{l}\text { Primary } \\
\text { diagnosis }\end{array}$ & $\begin{array}{l}\text { Comorbid } \\
\text { conditions }\end{array}$ & $\begin{array}{l}\text { Number of } \\
\text { Positive } \\
\text { items in } \\
\text { SCID-II-Q }\end{array}$ & $\begin{array}{l}\text { Duration } \\
\text { of main } \\
\text { problem }\end{array}$ & $\begin{array}{l}\text { Simultaneous medical } \\
\text { treatment in non-bold. } \\
\text { Prior treatments } \\
\text { in bold. }\end{array}$ & $\begin{array}{l}\text { Treatment } \\
\text { received }\end{array}$ \\
\hline $\begin{array}{l}\text { 3- } \\
\text { Minimally } \\
\text { improved }\end{array}$ & 7. Mona & 27 & Unemployed & $\begin{array}{l}\text { Living with } \\
\text { boyfriend }\end{array}$ & $\begin{array}{l}\text { Social phobia } \\
\text { (specific) }\end{array}$ & $\begin{array}{l}\text { Mixed } \\
\text { personality } \\
\text { disorder? }\end{array}$ & 48 & Lifelong & & $\begin{array}{l}\mathrm{I}-\mathrm{B}=3 \\
\mathrm{GW}=4 \\
\mathrm{G}-\mathrm{A}=4 \\
\mathrm{I}-\mathrm{A}=4\end{array}$ \\
\hline $\begin{array}{l}\text { 4-No } \\
\text { change }\end{array}$ & $\begin{array}{l}8 . \\
\text { Cecilia }\end{array}$ & 28 & Student & Married & $\begin{array}{l}\text { Social phobia } \\
\text { (specific) }\end{array}$ & & 9 & 12 years & & $\begin{array}{l}\mathrm{I}-\mathrm{B}=2 \\
\mathrm{GW}=5 \\
\mathrm{G}-\mathrm{A}=1 \\
\mathrm{I}-\mathrm{A}=0\end{array}$ \\
\hline
\end{tabular}

a McCullough et al. (2003) suggest that based on their clinical experience, a score above 20 on the SCID-II-Q indicates personality-related problems and a patient's need for personality-focused psychotherapy.

${ }^{b}$ I-B = number of individual therapy sessions before group week

$\mathrm{GW}=$ number of days attended in group week

$\mathrm{G}-\mathrm{A}=$ number of weekly group sessions after group week

$\mathrm{I}-\mathrm{A}=$ number of individual sessions after $\mathrm{G}-\mathrm{A}$ group sessions 


\section{Tables 3A to 3K: Outcome Data for the Nine Clients}

Table 3A. Niels ${ }^{\mathrm{d}}$ : Outcome data

\begin{tabular}{|c|c|c|c|}
\hline Scales & Pre $^{a}$ & Post $^{b}$ & Follow-up ${ }^{\mathrm{c}}$ \\
\hline $\mathrm{BAI}^{\mathrm{e}}$ & 37 & $17 \S^{\mathrm{f}}$ & $10 \S \#^{f}$ \\
\hline BDI-II & 30 & $20^{*}$ & $12 \S \#$ \\
\hline SPS & 57 & $27 \S$ & $13 \S \#$ \\
\hline SIAS & 60 & $33 \S$ & $23 \S \#$ \\
\hline SCL-90 & 2.16 & - & $.53 \S \#$ \\
\hline IIP-C & 1.73 & - & $.88 \S \#$ \\
\hline
\end{tabular}

Table 3B. Vera: Outcome data

\begin{tabular}{|l|l|l|l|}
\hline Scales & Pre & Post & Follow-up \\
\hline BAI & $9 \#$ & $0^{*}{ }^{f}$ & $5 \#$ \\
BDI-II & 14 & $5^{*} \#$ & $8 \#$ \\
SPS & $24 \#$ & $13^{* \#}$ & $15^{* \#}$ \\
SIAS & 34 & $18^{* \#}$ & $18^{* \#}$ \\
SCL-90 & $.47 \#$ & - & $.21 * \#$ \\
IIP-C & $.97 \#$ & - & $.59 * \#$ \\
\hline
\end{tabular}

Table 3C. Ann ${ }^{\mathrm{d}}$ : Outcome data

\begin{tabular}{|l|l|l|l|}
\hline Scales & Pre & Post & Follow-up \\
\hline BAI & 34 & $15 \S$ & $20 \S$ \\
BDI-II & 23 & $6 \S \#$ & $9 \S \#$ \\
SPS & 45 & $25 \S$ & $32 *$ \\
SIAS & 42 & $25 \S \#$ & 35 \\
SCL-90 & 1.67 & - & $1.04^{*}$ \\
IIP-C & 1.75 & - & $1.36^{*}$ \\
\hline
\end{tabular}

Table 3D. John ${ }^{\mathrm{d}}$ : Outcome data

\begin{tabular}{|l|l|l|l|}
\hline Scales & Pre & Post & Follow-up \\
\hline BAI & 25 & $13 \S$ & $5 \S \#$ \\
BDI-II & 15 & $11 \#$ & $5 * \#$ \\
SPS & 41 & 38 & $7 \S \#$ \\
SIAS & 59 & $38 \S$ & $18 \S \#$ \\
SCL-90 & 1.24 & - & $0.12 \S \#$ \\
IIP-C & $0.97 \#$ & - & $0.44 \S \#$ \\
\hline
\end{tabular}

Table 3E. Mary ${ }^{\mathrm{d}}$ : Outcome data

\begin{tabular}{|l|l|l|l|}
\hline Scales & Pre & Post & Follow-up \\
\hline BAI & 28 & 22 & 23 \\
BDI-II & 40 & $25 \S$ & $23 \S$ \\
SPS & 65 & $52^{*}$ & $55^{*}$ \\
SIAS & 61 & $47^{*}$ & $41 \S$ \\
SCL-90 & 2.07 & - & $1.34 \S$ \\
IIP-C & 1.98 & - & $1.53^{*}$ \\
\hline
\end{tabular}

Table 3F. Peter: Outcome data

\begin{tabular}{|l|l|l|l|}
\hline Scales & Pre & Post & Follow-up \\
\hline BAI & $2 \#$ & No data & $2 \#$ \\
BDI-II & $10 \#$ & & $8 \#$ \\
SPS & 30 & & $21 * \#$ \\
SIAS & 44 & & 52 \\
SCL-90 & $0.61 \#$ & & $.31 * \#$ \\
IIP-C & $0.81 \#$ & & $.36^{*} \#$ \\
\hline
\end{tabular}

Table 3G. Mona ${ }^{\mathrm{d}}$ : Outcome data

\begin{tabular}{|l|l|l|l|}
\hline Scales & Pre & Post & Follow-up \\
\hline BAI & $8 \#$ & 12 & No data \\
BDI-II & 13 & $7 \#$ & \\
SPS & 33 & $7 \S \#$ & \\
SIAS & 37 & $7 \S \#$ & \\
SCL-90 & $0.59 \#$ & - & \\
IIP-C & 1,42 & - & \\
\hline
\end{tabular}

Table 3H. Cecilia: Outcome data

\begin{tabular}{|l|l|l|l|}
\hline Scales & Pre & Post & Follow-up \\
\hline BAI & $4 \#$ & $6 \#$ & No data \\
BDI-II & $6 \#$ & $6 \#$ & \\
SPS & 25 & $15^{*} \#$ & \\
SIAS & $10 \#$ & $12 \#$ & \\
SCL-90 & $.34 \#$ & - & \\
IIP-C & $.55 \#$ & - & \\
\hline
\end{tabular}

Table 3I. Laila: Outcome data

\begin{tabular}{|l|l|l|l|}
\hline Scales & Pre & Post & Follow-up \\
\hline BAI & 19 & $12^{*}$ & 22 \\
BDI-II & 21 & $6 \S \#$ & $13^{*} \#$ \\
SPS & $22 \#$ & $19 \#$ & 30 \\
SIAS & $24 \#$ & 28 & 26 \\
SCL-90 & $-\mathrm{g}$ & - & $-\mathrm{g}$ \\
IIP-C & $-\mathrm{g}$ & - & $-\mathrm{g}$ \\
\hline
\end{tabular}

Table 3J. Mean $(S D)$ of Scales in standardization samples $\mathrm{h}$

\begin{tabular}{|l|l|l|}
\hline Scales & $\begin{array}{l}\text { Non-clinical } \\
\text { sample }\end{array}$ & Clinical sample \\
\hline BAI & $6.6(8.1)$ & $17.7(11.6)$ \\
BDI-II & $12.6(9.9)$ & $22.5(12.8)$ \\
SPS & $14.4(11.2)$ & $40.0(16.0)$ \\
SIAS & $18.8(11.8)$ & $34.6(16.4)$ \\
SCL-90 & $.45(.43)$ & $1.26(.68)$ \\
IIP-C & $.80(.54)$ & (No data) \\
\hline
\end{tabular}




\section{Tables 3A to 3K: Outcome data for the Nine Clients (continued)}

$\underline{\text { Notes to Table } 3 \mathrm{~A}-3 \mathrm{~J}}$

${ }^{\mathrm{a}}$ Pre $=$ at the beginning of therapy.

${ }^{\mathrm{b}}$ Post $=$ after 6 weeks of weekly group therapy.

${ }^{\mathrm{c}}$ Follow-up $=2$ months after the end of weekly group therapy, or at the end of further individual therapy.

${ }^{d}$ The following clients received individual therapy during the time between the post-treatment assessment and the follow-up assessment: Niels, Ann, John, Mary and Mona.

${ }^{\mathrm{e}}$ BAI: Beck Anxiety Inventory BDI-II: Beck Depression Inventory

SPS: Social Phobia Scale

SIAS: Social Interaction Anxiety Scale

SCL-90 (GSI): Symptom Checklist, 90-item version (Global Severity Index)

IIP-C: Inventory of Interpersonal Problems - Circumplex version.

$\mathrm{f}_{*}$ Statistically significant change (pre-to-post or pre-to-follow-up) (see Table $2 \mathrm{~K}$ below)

$\S$ Large change, i.e. at least more than $1 S D$ of the most relevant comparison group (pre-to-post or or pre-to-follow-up) (see Table 2Kbelow)

\# Within the normal rather than pathological range of functioning (see Table $2 \mathrm{~K}$ below).

g Scales not given to Laila because of her language problems.

${ }^{\mathrm{h}}$ See Appendix B for information on studies and samples.

Table 3K. Cut-Off Values for Different Definitions of Change (see Appendix B for calculations)

\begin{tabular}{|l|c|l|c|}
\hline & $\begin{array}{l}\text { Statistically significant } \\
\text { change }(*), \\
\text { change score } \geq\end{array}$ & $\begin{array}{l}\text { Large change } \\
(\S), . \\
\text { change score } \geq\end{array}$ & $\begin{array}{l}\text { Within normal range of } \\
\text { functioning }(\#), \\
\text { score } \leq\end{array}$ \\
\hline BAI & 7.5 & 11.6 & 11.2 \\
BDI-II & 7.3 & 12.8 & 16.9 \\
SPS & 7.6 & 16.0 & 24.9 \\
SIAS & 8.0 & 16.4 & 25.4 \\
SCL-90 & .21 & .68 & .76 \\
IIP-C & .30 & .54 & 1.34 \\
\hline
\end{tabular}


E. Hougaard, S.S. Madsen, L.M. Hansen, M. Jensen, G.S. Katborg,

L. Morsaa, M. Pedersen, S.M. Pedersen, \& J. Piet

Pragmatic Case Studies in Psychotherapy, http://pcsp.libraries.rutgers.edu

Volume 4, Module 4, Article 1, pp. 1-52, 12-15-08 [copyright by authors]

Table 4. Effect Sizes (d-scores) for the Whole Group

\begin{tabular}{|l|l|l|l|l|l|}
\hline Variable & $\begin{array}{l}\text { a Pre-treatment } \\
(\mathrm{N}=8) \\
\text { Mean }(S D)\end{array}$ & $\begin{array}{l}\text { Post-treatment } \\
(\mathrm{N}=8) \\
\text { Mean }(S D)\end{array}$ & $\begin{array}{l}\text { Follow-up } \\
(\mathrm{N}=7) \\
\text { Mean }(S D)\end{array}$ & $\begin{array}{l}\text { Pre-to-post } \\
(\mathrm{N}=8) \\
\text { d-value }\end{array}$ & $\begin{array}{l}\text { Pre-to-follow- } \\
\text { up (N=7) } \\
\text { d-value }\end{array}$ \\
\hline BAI ${ }^{\mathrm{b}}$ & $20.5(12.5)$ & $12.1(6.7)$ & $12.4(9.0)$ & $.83^{*}$ & $.86^{\S}$ \\
BDI-II & $20.3(10.8)$ & $10.8(7.6)$ & $11.1(5.9)$ & $1.02^{* *}$ & $1.27^{* *}$ \\
SPS & $39.0(16.0)$ & $24.5(14.7)$ & $24.7(16.1)$ & $.95^{* *}$ & $.98^{\S}$ \\
SIAS & $40.9(18.5)$ & $26.0(13.4)$ & $30.4(12.8)$ & $.92^{*}$ & $1.17^{\S}$ \\
SCL-90 (GSI) & $1.37(.72)^{\mathrm{a}}$ & - & $.59(.49)^{\mathrm{c}}$ & & $1.26^{*} \mathrm{c}$ \\
IIP-C & $1.37(.51)^{\mathrm{a}}$ & - & $.86(.49)^{\mathrm{c}}$ & & $1.02^{* *} \mathrm{c}$ \\
\hline
\end{tabular}

${ }^{\text {a }}$ Post-treatment is after 6 weeks of weekly group therapy.

Follow-up is 2 months after end of weekly group therapy or after further individual therapy.

${ }^{\mathrm{b}}$ Full names of scales in the footnotes to Table 2 .

${ }^{\mathrm{c}} \mathrm{N}=6$.

$* * \mathrm{p} \leq .01$

$* \mathrm{p} \leq .05$

$\S \mathrm{p} \leq .10$; all $\mathrm{p}$-values are two-tailed 
Volume 4, Module 4, Article 1, pp. 1-52, 12-15-08 [copyright by authors]

\section{Table 5. Clients Responding on Main Outcome Scales, SPS and SIAS, According to Different Criteria}

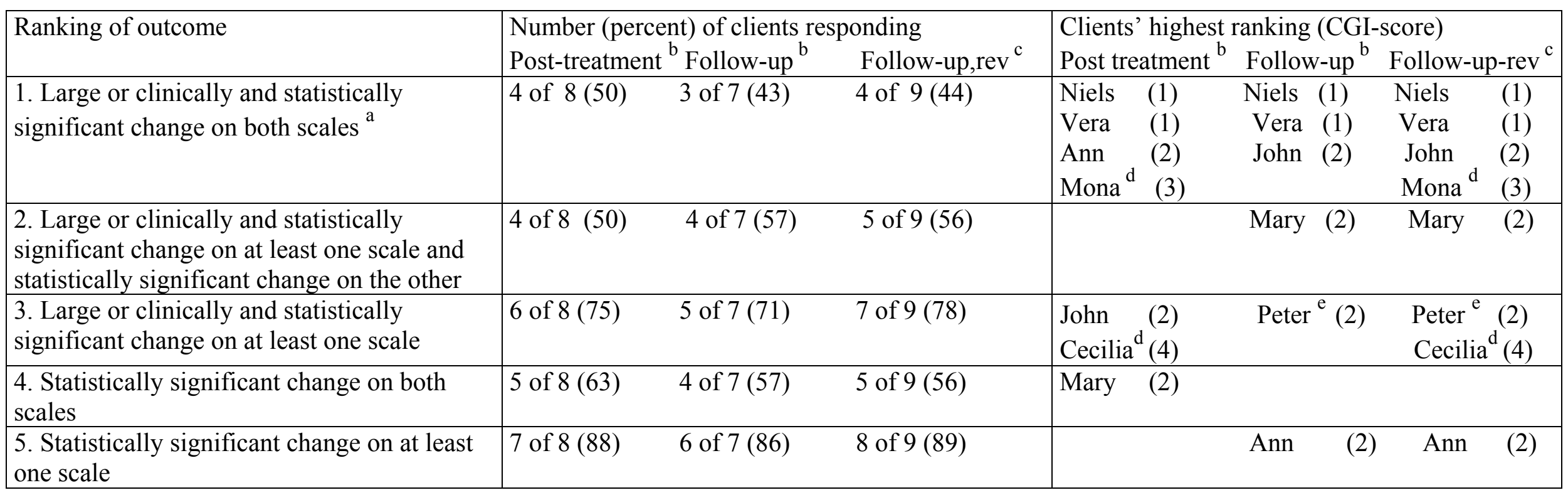

a Statistically significant change on a scale was calculated according to Jacobson and Truax's (1991) method (see text).

Clinical change on a scale is defined as "end-point status" (at post-treatment or at follow-up) below the cut-off point between a clinical and a non-clinical population on the scale

Large change on a scale is defined as positive change on the scale that is more than one $S D$ of the scale.

${ }^{\mathrm{b}}$ Figures based on number of clients filling out scales.

${ }^{\mathrm{c}}$ Follow-up revised: in this column, the post-treatment scores have been carried forward in case of missing follow-up data.

${ }^{\mathrm{d}}$ No follow-up data

${ }^{\mathrm{e}}$ No post treatment data

Note. The SPS is the Social phobia Scale, the SIAS, the Social Interaction Anxiety Scale, and the CGI is the Clinical Global Impression Scale. 
E. Hougaard, S.S. Madsen, L.M. Hansen, M. Jensen, G.S. Katborg,

L. Morsaa, M. Pedersen, S.M. Pedersen, \& J. Piet

Pragmatic Case Studies in Psychotherapy, http://pcsp.libraries.rutgers.edu

Volume 4, Module 4, Article 1, pp. 1-52, 12-15-08 [copyright by authors]

\section{Figure 1. Flowchart of Treatment and Data Points}

\section{Treatment}
Assessment and
Intensive-
Weekly group therapy (6
If indicated, further
individual treatment
week-program
(2-5 sessions)
( 5 sessions of 5 hours each)
Weeks 1-6
Week 7
sessions of 2 hours each)
individual therapy
(14-17 sessions)
Weeks 8-13
Weeks 14-32

\section{Data Points}

Pre-treatment

Post-group-treatment:

(weeks 1-4)

(week 13)

Follow-up:

(2 months after end of end of group treatment, or after end of individual therapy)

\section{Measures $^{\mathrm{a}}$ \\ BAI $^{b}$ \\ BDI-II \\ SPS \\ SIAS \\ SCL-90 \\ IIP-C}

BAI
BDI-II
SPS
SIAS
Evaluation of Social
$\quad$ Phobia Scales (see
$\quad$ Appendix A)

BAI

BDI-II

SPS

SIAS

SCL-90

IIP-C

CGI (Clinical Global

Impression Scale)

${ }^{\text {a }}$ All measures completed by the client expect the CGI.

b BAI: Beck Anxiety Inventory; BDI-II: Beck Depression Inventory; SPS: Social Phobia Scale; SIAS: Social Interaction Anxiety Scale; SCL-90: Symptom Checklist, 90-item version; IIP-C: Inventory of Interpersonal Problems - Circumplex version; CGI: Clinical Global Impression. 


\section{Figure 2A to 2I: Changes in Evaluation of Social Phobia Scales During the Intensive Group Week}

Fig 2A. Niels: Individualized scale change in the intensive group-week (average scores for phobias, safety behavior and negative thoughts)

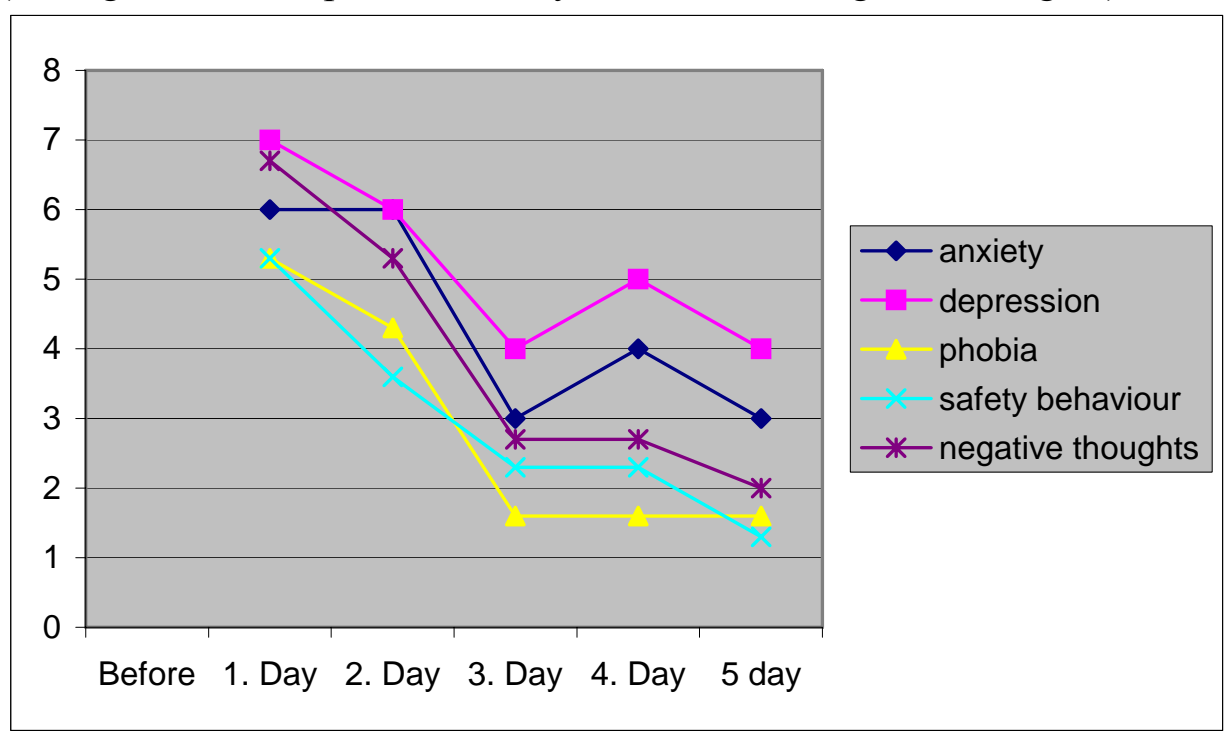

Phobias: 1. Eating together with others, 2. Start a conversation, 3. Be in class

Safety behaviors: 1 . Engaging in activities, 2. Folds hands, 3. Avoids eye contact

Negative thoughts: 1. I can't handle to be social, 2. I am weak and fragile, 3. Others can se that I am unwell

Fig 2B. Vera: Figure is not given because of misunderstandings (cf. case vignette for Vera).

Fig 2C. Ann: Individualized scale change in the intensive group-week (average scores for phobias, safety behavior and negative thoughts)

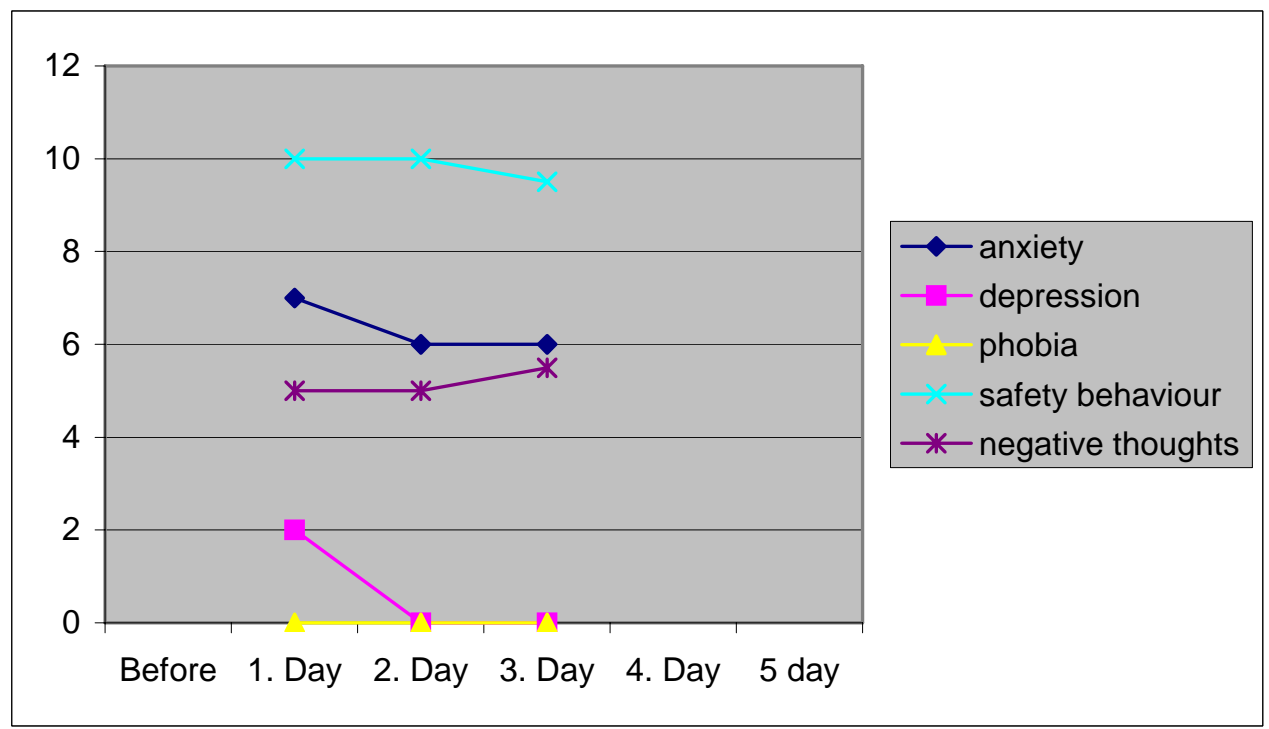

Phobias: 1. Saying something in a group, 2. Eating in the canteen

Safety behaviors: 1 . Monitoring anxiety symptoms, 2. Letting hair hang down Negative thoughts: 1 . They think I am stupid or weak, 2. They don't like me 
Phobia in a Training Setting: A Case Study of One Treatment Group with Nine Clients

E. Hougaard, S.S. Madsen, L.M. Hansen, M. Jensen, G.S. Katborg,

L. Morsaa, M. Pedersen, S.M. Pedersen, \& J. Piet

Pragmatic Case Studies in Psychotherapy, http://pcsp.libraries.rutgers.edu

Volume 4, Module 4, Article 1, pp. 1-52, 12-15-08 [copyright by authors]

\section{Figure 2 (continued)}

Fig 2D. John. Individualized scale change in the intensive group-week (average scores for phobias, safety behavior and negative thoughts)

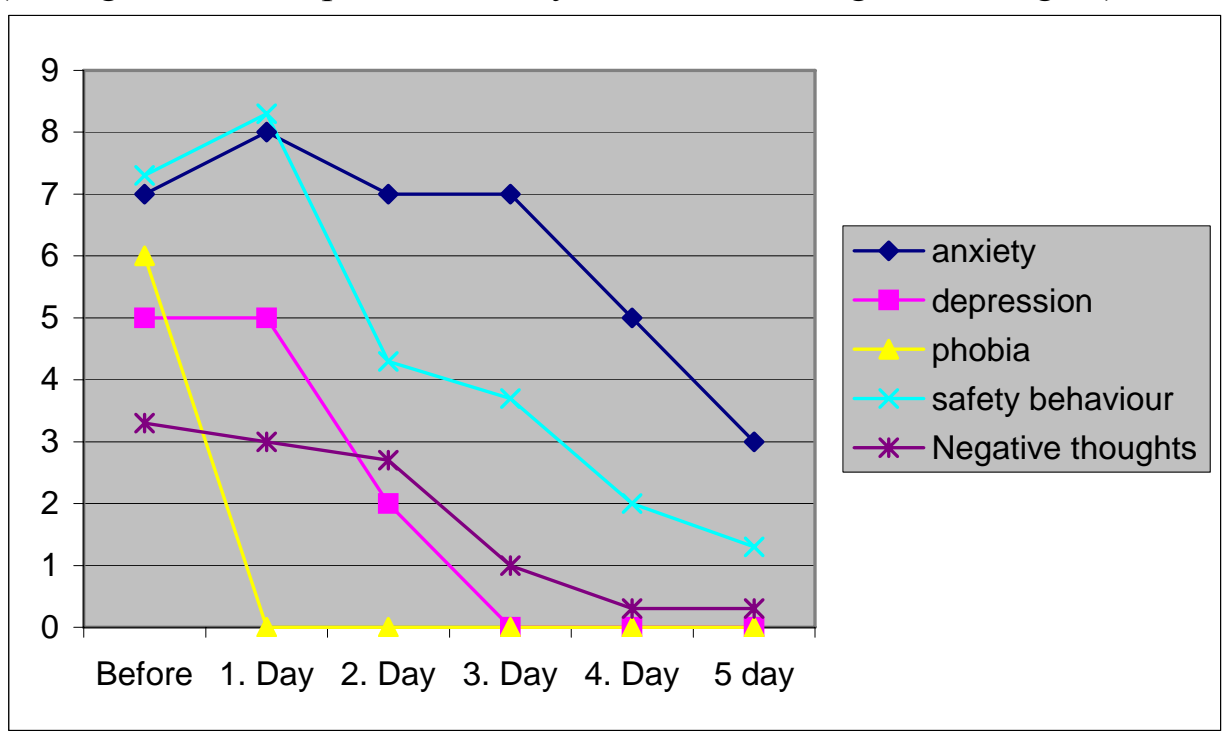

Phobias*: 1. Being in large groups (over about 10 persons), 2. Eating with unknown people, 3. Saying something in a group

Safety behaviors: 1. Avoids eye contact, 2. Eats or drinks little, 3. Monitors bodily sensations Negative thoughts: 1 . They can see I am nervous, 2. I am boring, 3. I look peculiar

Fig 2E. Mary: Individualized scale changes in the intensive group-week (average scores for phobias, safety behavior and negative thoughts)

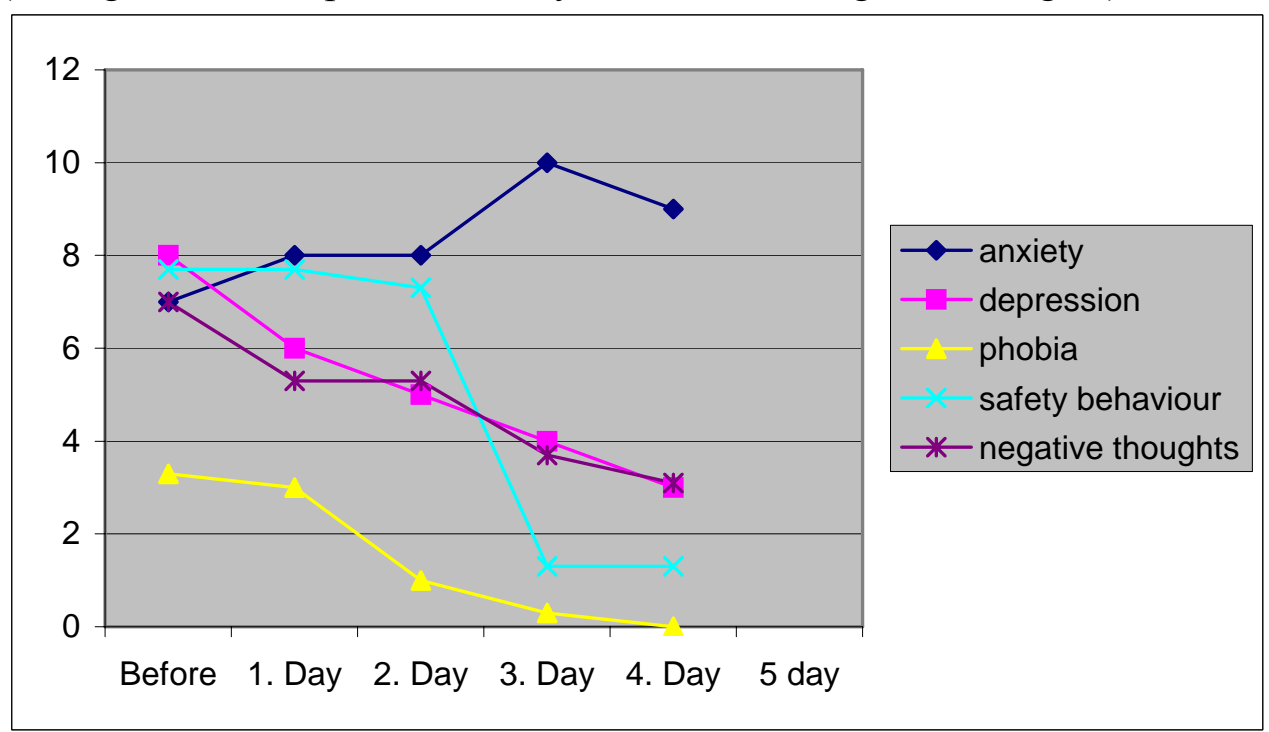

Phobias: 1. Giving a presentation, 2. Speaking to someone in class, 3. Tête-à-tête conversations Safety behaviors: 1 . Over-preparing in head what to say, 2. Chewing gum, 3. Speaking fast Negative thoughts: 1. Everybody is looking at me, 2. I am stupid and ugly, 3. They don't like me 
Figure 2 (continued)

Fig 2F. Peter: Individualized scale changes in the intensive group-week (average scores for phobias, safety behavior and negative thoughts)

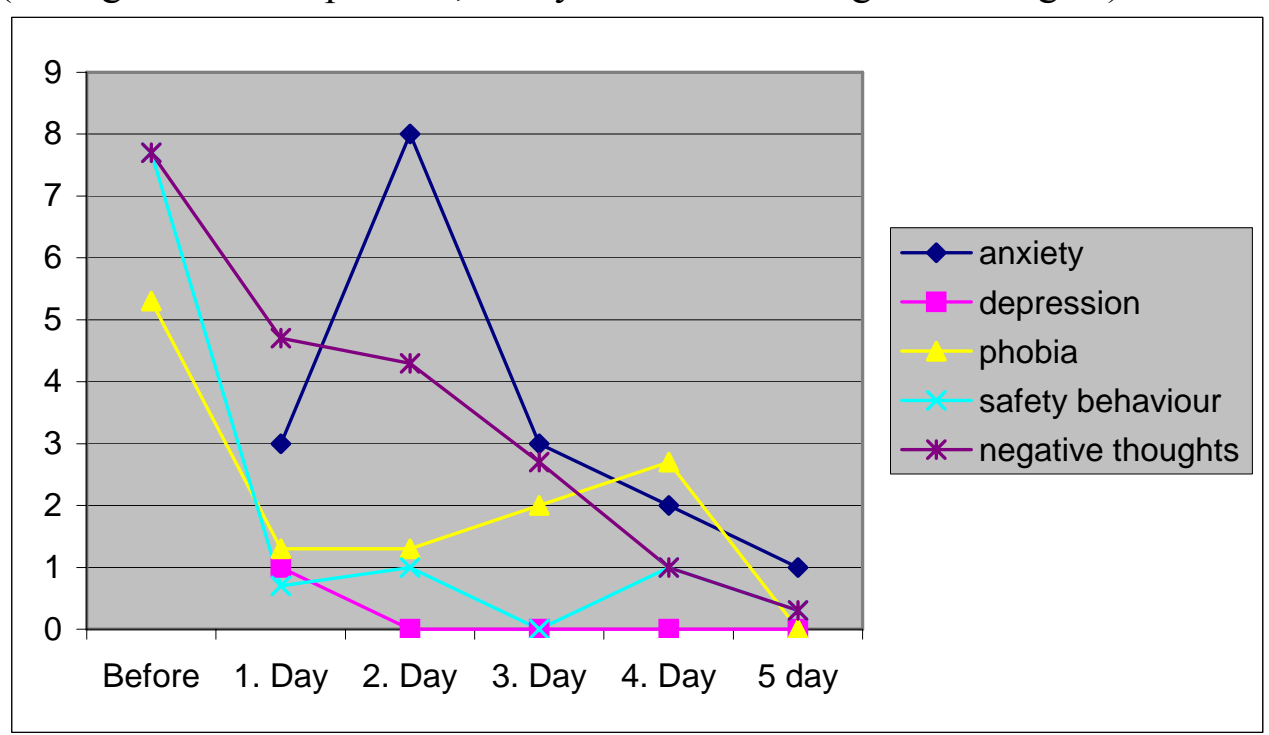

Phobias: 1. Give a presentation or speak, 2. Express criticism of others, 3. Situations where he might blush Safety behaviors: 1 . Over-prepares, 2. Monitors his overview of what to say, 3. Tries to arrive as one of the first persons (so he does not have to chose who to sit next to)

Negative thoughts: 1 . I loose the thread/black-out, 2. I am not good enough, 3. I am week and cannot really join the group.

Fig 2G. Mona: Individualized scale change in the intensive group-week (average scores for phobias, safety behavior and negative thoughts)

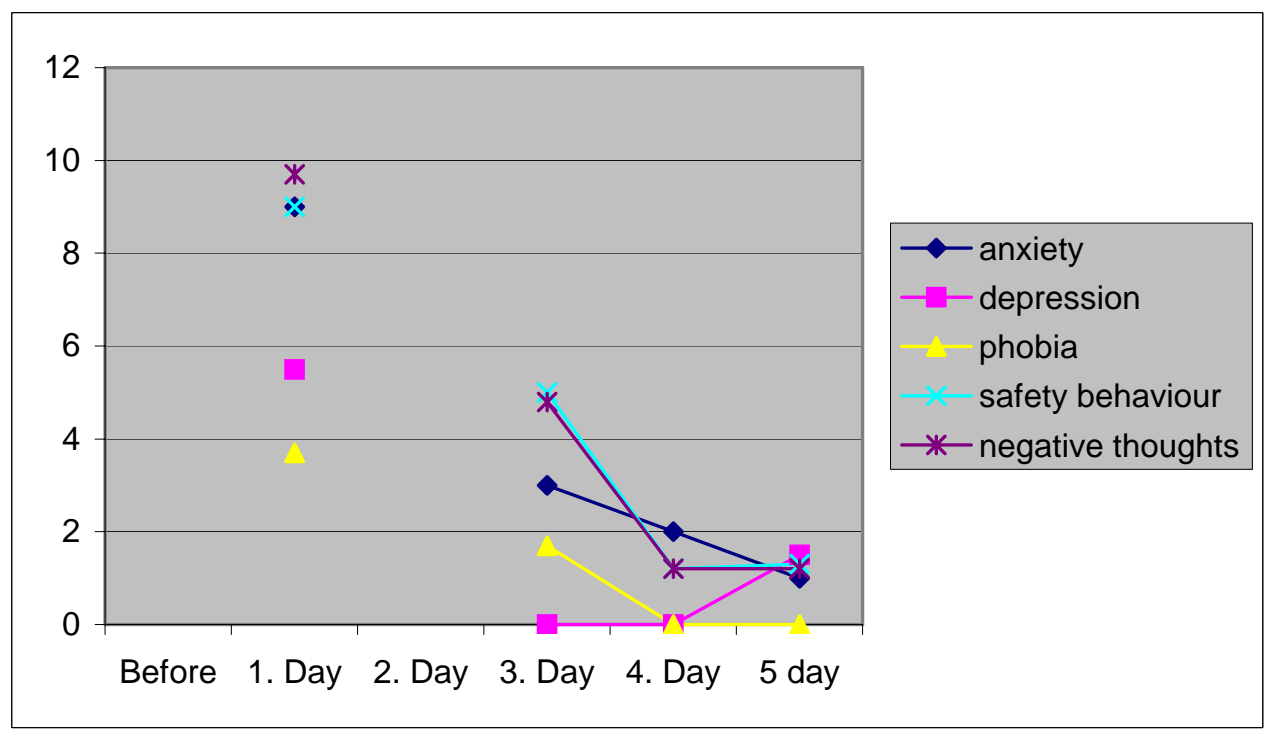

Phobias: 1. Saying something in a group, 2. Express disagreement, 3. Applying for a job

Safety behaviors: 1 . Over-preparing what to say, 2. Cares a lot about her appearance, 3 . Repeats in head what to say

Negative thoughts: 1. Everybody is staring at me, 2. I loose control, 3. Others don't like me 
Phobia in a Training Setting: A Case Study of One Treatment Group with Nine Clients

E. Hougaard, S.S. Madsen, L.M. Hansen, M. Jensen, G.S. Katborg,

L. Morsaa, M. Pedersen, S.M. Pedersen, \& J. Piet

Pragmatic Case Studies in Psychotherapy, http://pcsp.libraries.rutgers.edu

Volume 4, Module 4, Article 1, pp. 1-52, 12-15-08 [copyright by authors]

\section{Figure 2 (continued)}

Fig 2H. Cecilia: Individualized scale change in the intensive group-week (average scores for phobias, safety behavior and negative thoughts)

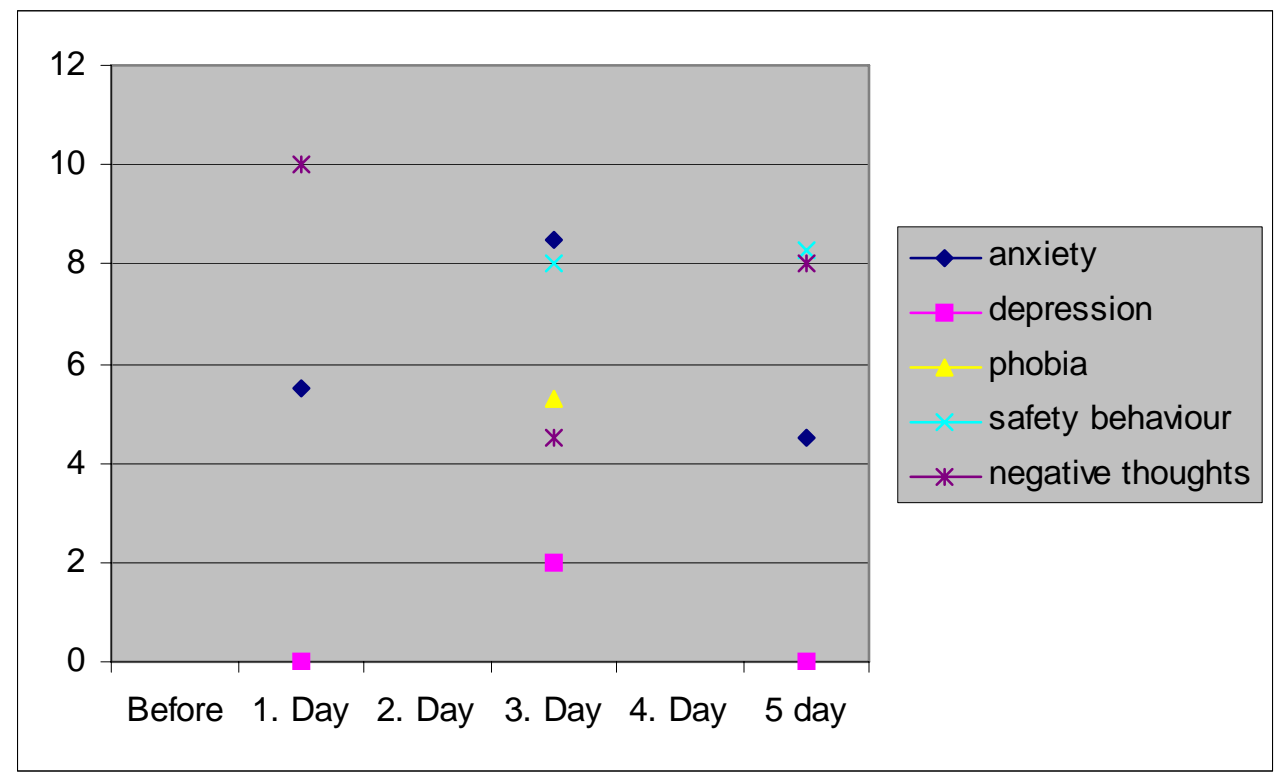

Phobias: 1. Giving a presentation, 2. Saying something in the group

Safety behaviors: 1 . Monitoring bodily sensations, 2 . Speaking fast, 3 . Avoid pauses

Negative thoughts: 1. I will say something stupid, 2. I will do or say something wrong

Figure 2I. Laila

Laila did not fill in the individualized scales because of problems with her Danish language (cf. case vignette on Laila). 
A Novel Group Therapeutic Format in Cognitive Behavioral Treatment for Clients with Social

Phobia in a Training Setting: A Case Study of One Treatment Group with Nine Clients

E. Hougaard, S.S. Madsen, L.M. Hansen, M. Jensen, G.S. Katborg,

L. Morsaa, M. Pedersen, S.M. Pedersen, \& J. Piet

Pragmatic Case Studies in Psychotherapy, http://pcsp.libraries.rutgers.edu

Volume 4, Module 4, Article 1, pp. 1-52, 12-15-08 [copyright by authors]

\section{Appendix A. Evaluation of Social Phobia (daily version)}

Name:

Date:

For all questions: Evaluate for the latest day (fill out in the evening or early next morning)

Use the scale from 0-10 for graduating your answer

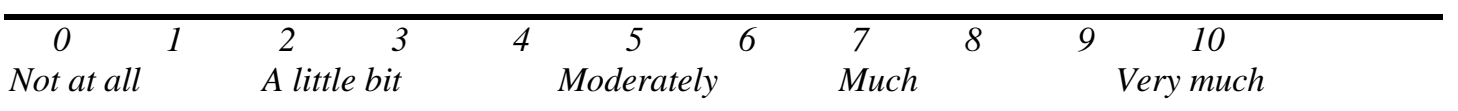

1. How much have you been worried or anxious? (0-10):

2. How much have you been in a bad mood or depressed? (0-10):

3. To what extent have you avoided your most feared social situations? Mention your most feared situation from your problem list and judge how much you have tried to avoid the situation on the scale from $0-10$, where 10 corresponds to $100 \%$, i.e., you have totally avoided the situation:

Nr. 1

Nr. 2

Nr. 3
Avoidance (0-10):

Avoidance (0-10):

Avoidance (0-10):

4. To what extent have you used your most preferred forms of safety behavior, when you were in a feared situation? Mention your most preferred forms of safety behavior and judge how much you have used them on the scale from 0-10, where 10 corresponds to all the time, and 5 to about half of time in the feared situations:

Nr. 1

Nr. 2

Nr. 3
Extent of use (0-10):

Extent of use (0-10):

Extent of use (0-10):

5. How much have you believed in your most common negative, anxiety provoking thoughts about what might happen in the feared social situations. Mention what your thoughts are and judge your degree of belief in the thought on the scale from $0-10$, where 10 corresponds to a $100 \%$ belief in the thought, i.e., you are absolutely sure that the thought is correct.

Nr. 1 Belief in the thought (0-10):

Nr. 2 Belief in the thought (0-10):

Nr. 3 Belief in the thought $(0-10)$ : 


\section{Appendix B: Measuring change}

Statistical significant or reliable change (RC), according to Jacobson \& Truax (1991), is calculated in the following way:

$$
\mathrm{SE}(\text { standard error of measurement })=\mathrm{SD} \times\left(1-\mathrm{r}_{\mathrm{xx}}\right)^{1 / 2}
$$

where SD is the standard deviation of the non-clinical group and $r_{x x}$ is Cronbach's alpha

$\mathrm{SE}_{\text {diff }}$ (standard error of differences $)=\left(2 \times \mathrm{SE}^{2}\right)^{1 / 2}$

$\mathrm{RC}=1.96 \times \mathrm{SE}_{\mathrm{diff}}$

The clinical significant cut-off point ( $\left.\mathrm{CS}_{\text {cut-off }}\right)$, according to Jacobson \& Truax (1991), is calculated as:

$$
\begin{aligned}
& \mathrm{CS}_{\text {cut-off }}=\left(\mathrm{M}_{\text {clin }} \times \mathrm{SD}_{\text {norm }}\right)+\left(\mathrm{M}_{\text {norm }} \times \mathrm{SC}_{\text {clin }}\right) \\
& \mathrm{SD}_{\text {norm }}+\mathrm{SD}_{\text {clin }}
\end{aligned}
$$

Where $\mathrm{M}_{\text {clin }}$ and $\mathrm{M}_{\text {norm }}$ are the mean scores of the "dysfunctional" and the "functional population", respectively, and $\mathrm{SD}_{\text {norm }}$ and $\mathrm{SD}_{\text {clin }}$ are the standard deviations in these two groups

The values for and the results from the calculations with different measures are given below:

\section{Beck Anxiety Inventory (BAI)}

Clients with social phobia $(\mathrm{n}=44): \underline{\mathrm{M}}(\underline{\mathrm{SD}})=17.7$ (11.6) (Beck \& Steer, 1993a)

Non-clinical community sample $(\mathrm{n}=242): \underline{\mathrm{M}}(\underline{\mathrm{SD}})=6.6(8.1)$ (Gillis, Haaga \& Ford, 1995)

Cronbach's alpha, non-clinical samples (meta-analysis of 23 studies) $=.89$ (De Ayala,

Vonderharr-Carlson \& Kim, D, 2005).

$\mathrm{RC}=7.5 ; \mathrm{CS}_{\text {cut-off }}=11.2$

\section{Beck Depression Inventory, second version (BDI-II)}

Mixed clinical sample of outpatients $(\mathrm{n}=500)$ : $\underline{\mathrm{M}}(\underline{\mathrm{SD}})=22.5$ (12.8) (Beck, Steer \& Brown, 1996)

Non-clinical samples (college students, $\mathrm{n}=120)$ ): $\underline{\mathrm{M}}(\underline{\mathrm{SD}})=12.6$ (9.9) (Beck et al., 1996).

Cronbach's alpha, non-clinical samples (college students, $\mathrm{n}=120)=.92$ (Beck et al., 1996).

$\mathrm{RC}=7.3 ; \mathrm{CS}_{\text {cut-off }}=16.9$.

\section{Social Phobia Scale (SPS)}

Clients with social phobia $(\mathrm{n}=243): \underline{\mathrm{M}}(\underline{\mathrm{SD}})=40.0$ (16.0) (Mattick \& Clark, 1998)

Non-clinical community sample $(\mathrm{n}=315): \underline{\mathrm{M}}(\underline{\mathrm{SD}})=14.4$ (11.2) (Mattick \& Clark, 1998)

Cronbach's alpha, mixed sample $=.94$ (Mattick \& Clark, 1998)

$\mathrm{RC}=7.6 ; \mathrm{CS}_{\text {cut-off }}=24.9$

\section{Social Interaction Anxiety Scale (SIAS)}

Clients with social phobia $(\mathrm{n}=243): \underline{\mathrm{M}}(\underline{\mathrm{SD}})=34.6(16.4)$

Non-clinical community sample $(\mathrm{n}=315): \underline{\mathrm{M}}(\underline{\mathrm{SD}})=18.8(11.8)$

Cronbach's alpha, mixed sample $=.94$ (Mattick \& Clark, 1998)

$\mathrm{RC}=8.0 ; \mathrm{CS}_{\text {cut-off }}=25.4$ 
E. Hougaard, S.S. Madsen, L.M. Hansen, M. Jensen, G.S. Katborg,

L. Morsaa, M. Pedersen, S.M. Pedersen, \& J. Piet

Pragmatic Case Studies in Psychotherapy, http://pcsp.libraries.rutgers.edu

Volume 4, Module 4, Article 1, pp. 1-52, 12-15-08 [copyright by authors]

\section{Appendix B: Measuring change (continued)}

\section{Symptom Checklist, 90-item version (SCL-90)}

Psychiatric outpatients $(\mathrm{n}=1002): \underline{\mathrm{M}}(\underline{\mathrm{SD}})=1.26(.68)($ Derogatis, 1977)

Danish non-clinical community sample $(\mathrm{n}=1153): \underline{\mathrm{M}}(\underline{\mathrm{SD}})=.45(.43)$ (Olsen, Mortensen $\&$ Bech, 2004)

Cronbach's alpha, Danish non-clinical community sample $=.97$ (personal communication from Erik Lykke Mortensen, value not given in Olsen et al., 2004)

$\mathrm{RC}=.21 ; \mathrm{CS}_{\text {cut-off }}=.76$

\section{Inventory of Interpersonal Problems - Circumplex version (IIP-C)}

Non-clinical community sample $(\mathrm{n}=800): \underline{\mathrm{M}}(\underline{\mathrm{SD}})=.80(.54)$

Cronbach's alpha $=.96$

$\mathrm{RC}=.30$ 